\title{
Time-Varying U.S. Inflation Dynamics and the New Keynesian Phillips Curve*
}

\author{
Kevin J. Lansing ${ }^{\dagger}$ \\ Federal Reserve Bank of San Francisco
}

June 2, 2006

\begin{abstract}
This paper introduces a form of boundedly-rational expectations into an otherwise standard New-Keynesian Phillips curve. The representative agent's forecast rule is optimal (in the sense of minimizing mean squared forecast errors), conditional on a perceived law of motion for inflation and observed moments of the inflation time series. The perceived law of motion allows for both temporary and permanent shocks to inflation, the latter intended to capture the possibility of evolving shifts in the central bank's inflation target. In this case, the agent's optimal forecast rule defined by the Kalman filter coincides with adaptive expectations, as shown originally by Muth (1960). I show that the perceived optimal value of the gain parameter assigned to the last observed inflation rate is given by the fixed point of a nonlinear map that relates the gain parameter to the autocorrelation of inflation changes. The model allows for either a constant gain or variable gain, depending on the length of the sample period used by the agent to compute the autocorrelation of inflation changes. In the variable-gain setup, the equilibrium law of motion for inflation is nonlinear and can generate time-varying inflation dynamics similar to those observed in long-run U.S. data. The model's inflation dynamics are driven solely by white-noise fundamental shocks propagated via the expectations feedback mechanism; all monetary policy-dependent parameters are held constant.
\end{abstract}

Keywords: Inflation Expectations, Phillips Curve, Time-Varying Persistence $\mathcal{G}$ Volatility.

JEL Classification: E31, E37.

\footnotetext{
${ }^{*}$ For helpful comments and suggestions, I thank participants at the 2006 Meeting of the Society for Nonlinear Dynamics and Econometrics and the 2006 Midwest Macroeconomics Meeting. The views in this paper are my own and not necessarily those of the Federal Reserve Bank of San Francisco or of the Federal Reserve System.

$\dagger$ Research Department, Federal Reserve Bank of San Francisco, P.O. Box 7702, San Francisco, CA 94120-7702, (415) 974-2393, FAX: (415) 977-4031, email: kevin.j.lansing@sf.frb.org, homepage: www.frbsf.org/economics/economists/klansing.html
} 


\section{Introduction}

\subsection{Overview}

The standard New Keynesian Phillips Curve (NKPC) is derived most straightforwardly from Calvo's (1983) model of sticky price adjustment. Under rational expectations, the Calvo model implies that the equilibrium inflation rate is nearly a jump variable. Numerous researchers have criticized the standard NKPC on grounds that a reasonably parameterized version fails to capture important features of post-World War II U.S. data, namely, high levels of inflation persistence and the delayed and gradual response of inflation to unanticipated monetary policy shocks. ${ }^{1}$ Efforts to "fix up" the standard NKPC have generally involved the introduction of lagged inflation (or some function thereof) into the equilibrium law of motion. Modified versions of the NKPC have been motivated by the presence of some backward-looking agents (Roberts 1997, Galí and Gertler 1999), alternative wage contracts (Buiter and Jewitt 1981, Fuhrer and Moore 1995), the use of backward-looking price indexation by firms (Woodford 2003, Christiano, Eichenbaum, and Evans 2005), sticky information adjustment (Mankiw and Reis 2002), learning or signal extraction about the central bank's inflation target or other fundamentals (Erceg and Levin 2003, Collard and Dellas 2005), and continuously evolving but nevertheless unanticipated shifts in the inflation target (Kozicki and Tinsley 2002, Cogley and Sbordone 2005).

While modified versions of the NKPC have achieved varying degrees of success in matching the data, most continue to rely on some argument that agents fail to optimize in an important way or, alternatively, suffer from the drawback that agents will eventually learn the underlying fundamentals that govern their environment, thus restoring the full-information, rational expectations solution. The model developed in this paper is intended to address such criticisms, at least in part. I develop a boundedly-rational NKPC that can produce time-varying inflation dynamics similar to those observed in long-run U.S. data. The model employs the concept of a "consistent expectations equilibrium" described by Hommes and Sorger (1998). In this type of equilibrium, the representative agent's forecast rule is parameterized to match the observed correlation structure of the forecast variable. The resulting forecast errors exhibit near-zero autocorrelation at all lags, rendering it difficult for the agent to detect a misspecification of the forecast rule. This is closely related to the concept of a "restricted perceptions equilibrium" described by Evans and Honkopohja (2001). In this type of equilibrium, the agent's forecast rule is optimized (in the sense of minimizing mean squared forecast errors) for a perceived law of motion that does not nest the actual law of motion as a special case.

Klein (1978) and Barsky (1987) were among the first to call attention to the dramatic changes in inflation persistence in long-run U.S. data. Barsky (p. 3) noted that "[i]inflation evolved from essentially a white noise process in the pre-World War I years, to a highly persistent, non-stationary ARIMA process in the post-1960 period." More recently, Cogley and Sargent $(2001,2005)$ employ vector autoregressions that allow for drifting coefficients and stochastic volatility to document the evolving nature of U.S. inflation dynamics in postWorld War II data. Their methodology identifies a positive correlation between measures of persistence, volatility, and the level of inflation in post-World War II data. Simple 20-year rolling summary statistics confirm these basic findings. As a caveat, it should be noted that

\footnotetext{
${ }^{1}$ See, for example, Roberts (1997, 2005), Fuhrer (1997, 2005), Mankiw (2001), and Rudd and Whelan (2005a, 2005b), among others.
} 
findings of time-varying inflation persistence in recent data are not universal. Pivetta and Reis (2004) argue that the wide confidence intervals around measures of inflation persistence do not allow one to reject the hypothesis of no change in persistence since 1965. These authors do find robust evidence of a decline in inflation volatility, however.

Shifts in monetary policy are an obvious candidate for explaining changes in inflation dynamics. Both Klein (1978) and Barsky (1987) attribute the change in inflation persistence after World War I to the abandonment of the classical gold standard. A gold standard can be viewed as a price-level targeting regime. Under an inflation-targeting regime, shifts in the central bank's inflation target (which determines the trend inflation rate) can distort standard measures of persistence and volatility. For this reason, measures of persistence and volatility should be conditioned on an estimate of trend inflation. ${ }^{2}$ In computing the 20-year rolling summary statistics, I control for shifts in trend inflation by first extracting the low-frequency component of U.S. inflation. Detrended inflation continues to exhibit time-varying patterns of persistence and volatility, even during periods of seemingly-unchanged monetary policy, such as the sample period since 1995. Such observations suggest that U.S. inflation is driven by a number of different nonlinearities, not just those attributable to policy regime shifts.

In the model, the representative agent's perceived law of motion allows for both temporary and permanent shocks to inflation, the latter intended to capture the possibility of evolving shifts in the central bank's inflation target. In this case, the agent's optimal forecast rule defined by the Kalman filter coincides with adaptive expectations, as shown originally by Muth (1960). I show that the perceived optimal value of the gain parameter assigned to the last observed inflation rate is given by the fixed point of a nonlinear map that relates the gain parameter to the autocorrelation of inflation changes. By computing the value of the autocorrelation coefficient, the agent can identify the "signal-to-noise ratio," which measures the relative variances of the permanent and temporary shocks to inflation. A higher signalto-noise ratio calls for a higher gain parameter which, in turn, places more weight on recent inflation data in the agent's forecast rule.

The model allows for either a constant gain or variable gain, depending on the length of the sample period used by the agent to identify the signal-to-noise ratio from the observed autocorrelation of inflation changes. As the sample period becomes infinitely long, the equilibrium yields a constant gain. A rolling sample period yields a variable gain. In either setup, the agent's forecast errors are close to white noise. In the variable-gain setup, the equilibrium law of motion for inflation is nonlinear and therefore capable of generating stochastic persistence and volatility. This version of the model can also generate positive skewness, excess kurtosis, and episodes where measures of persistence, volatility, and the level of inflation exhibit positive correlation with each other. All of these features are present in long-run U.S. inflation data. From the agent's perspective, the use of a variable-gain forecasting algorithm is justified by movements in the perceived signal-to-noise ratio. The model's methodology for identifying the perceived signal-to-noise ratio can also be applied directly to U.S. inflation data. The U.S. signal-to-noise ratio identified in this way exhibits an upward drift during the 1970s, followed by downward drift from the mid-1990s onwards. This pattern suggests that the perceived signal-to-noise ratio might be viewed as a inverse measure of the Fed's credibility for maintaining a constant inflation target.

In the model, the driving variable for inflation can be interpreted as either the output gap

\footnotetext{
${ }^{2}$ This point has been emphasized by Kozicki and Tinsley (2002), Levin and Piger (2004), and Marques (2004), among others.
} 
or real marginal cost. Monetary policy can operate implicitly through two channels: (i) the trend inflation rate around which the NKPC is log-linearized-assumed here to be zero, or (ii) the parameters that govern the exogenous stochastic process for the driving variable. The policy-dependent parameters are held constant throughout the analysis in order to isolate the effects of expectational feedback on the dynamics of inflation. Interestingly, the model can generate pronounced low-frequency swings in the level of inflation that have nothing to do with changes in monetary policy. From the agent's perspective, the observed low-frequency swings justify the use of a forecast rule that allows for permanent shifts in the central bank's inflation target. This feature of the model bears similarity to the "self-confirming equilibrium" concept described by Sargent (1999).

Introducing actual changes in monetary policy would add further complexity to the model's inflation dynamics. In this regard, it should be noted that log-linearization of the Calvo pricing equation around a non-zero trend inflation rate would significantly alter the form of the standard NKPC. ${ }^{3}$ The altered form of the NKPC is employed in the empirical studies of Kozicki and Tinsley (2002) and Cogley and Sbordone (2005). These studies implicitly assume that the agent in the model perceives the non-zero trend inflation rate to be constant. The model is then estimated using data which suggests that the actual trend inflation rate is shifting. By contrast, in the models of Erceg and Levin (2003) and Kozicki and Tinsley (2005), both the perceived and actual trend inflation rates shift over time. In this paper, the agent's perception is that the trend inflation rate is shifting. This perception turns out to be consistent with the agent's observations (as measured by the low-frequency component of inflation), even though the actual trend inflation rate in the model is held constant.

\subsection{Other Related Literature}

The use of boundedly-rational (or behavioral) inflation expectations in macroeconomic models is motivated by numerous empirical studies. Survey-based measures of U.S. inflation expectations tend to systematically underpredict actual inflation in the sample period prior to October 1979 and systematically overpredict it thereafter. Rational inflation expectations would not give rise a sustained sequence of one-sided forecast errors. Roberts (1997), Carroll (2003), Mankiw, Reis, and Wolfers (2004), Branch (2004), and Adam and Padula (2003) all find evidence that survey-based measures of U.S. inflation expectations do not make the most efficient use of available information.

The boundedly-rational form of adaptive expectations used here is similar to that explored by Evans and Ramey (2006) in the context of the Lucas (1973) monetary policy model. In their framework, the value of the gain parameter is pinned down using a Nash equilibrium concept, but this turns out to coincide with the value implied by a particular restricted perceptions equilibrium. Their analysis examines the importance of the Lucas critique in an economy with monetary policy regime shifts.

An empirical study by Ball (2000) allows for a switch between two forms of "near-rational" forecast rules to help account for the dramatic change in U.S. inflation persistence identified by Klein (1978) and Barsky (1987). In Ball's framework, the switch between forecast rules is taken as given; it is not modeled as the endogenous outcome of an actual or perceived shift in monetary policy.

\footnotetext{
${ }^{3}$ See Ascari (2004) and Sahuc (2006).
} 
Orphanides and Williams (2005) and Milani (2005) introduce inflation persistence in the form of constant-gain learning in models where the underlying fundamentals do not shift. The representative agent's perceived law of motion for inflation is an $\operatorname{AR}(1)$ process with parameters that are perpetually re-estimated using recent data. The value of the gain parameter in the learning algorithm is calibrated rather than endogenized within the model itself. In the learning model of Erceg and Levin (2003), the value of the gain parameter is estimated by minimizing the squared deviations between the model's inflation expectations and surveybased U.S. inflation expectations.

Lastly, recent papers by Mash (2004) and Sheedy (2005) show that lagged inflation can be introduced into a fully-rational NKPC by replacing the Calvo-model assumption of a constant probability of price change with a more-realistic assumption of a rising hazard function, i.e., the probability rises with the age of the price. It still appears to be the case, however, that a reasonably-calibrated version of this setup fails to match the high levels of inflation persistence in post-World War II U.S. data. Moreover, Whelan (2006) shows that, like the Calvo-model, the rising hazard function model predicts a counterfactual negative coefficient on lagged inflation in reduced-form Phillips curve regressions. The rising hazard function model also cannot account for the time-varying inflation dynamics observed in U.S. data since 1995.

\section{Time-Varying Persistence and Volatility in U.S. Inflation}

Figure 1 provides evidence of time-varying persistence and volatility in long-run U.S. inflation data. The left-side panels plot the data and 20-year rolling summary statistics for CPI inflation from 1871.Q1 to 2004.Q4. The right-side panels plot the same information for GDP price inflation from 1949.Q1 to 2004.Q4. ${ }^{4}$ The 20-year rolling summary statistics are computed for both the raw and detrended inflation series. ${ }^{5}$ As noted in the introduction, detrending is a way to control for shifts in the central bank's inflation target that have occurred over time.

Panel 1a illustrates the dramatic difference in the behavior of pre- and post-World War I inflation noted by Klein (1978) and Barsky (1987). The simple measure of persistence used here is the 20-year rolling autocorrelation coefficient. ${ }^{6}$ Persistence hovers close to zero during the pre-World War I era but then starts to increase around the year 1915 (panel 1c). There are some notable variations in persistence over the ensuing decades, followed by a sharp drop in the rolling autocorrelation towards the end of the sample. The end-of-sample drop in persistence is also evident in GDP price inflation (panel 1d).

\footnotetext{
${ }^{4}$ The annualized 1-quarter inflation rate is given by $4 \log \left(P_{t} / P_{t-1}\right)$, where $P_{t}$ is the relevant price index. The quarterly CPI data were constructed by averaging monthly CPI data obtained from Robert Shiller's website: http://www.econ.yale.edu/ shiller/data/ie_data.htm. Shiller's data employs the CPI-U (Consumer Price Index-All Urban Consumers) published by the U.S. Bureau of Labor Statistics from 1913 onward. For prior years, Shiller's price index is constructed by splicing to monthly price data obtained from Warren and Pearson (1935, Table 1, pp. 11-14). Data on the quarterly GDP price index is from http://research.stlouisfed.org/fred2/series/GDPCTPI.

${ }^{5}$ Thoroughout the paper, the inflation trend is defined as the low-frequency component of the data (fluctuations longer than 32 quarters) extracted using the band pass filter approximation of Christiano and Fitzgerald (2003). Similar results are obtained if the data are detrended using the Hodrick-Prescott filter with a smoothing parameter of 1600 .

${ }^{6}$ Another commonly-used measure of persistence is the sum of the autoregressive coefficients in a univariate regression. In the case of an $\operatorname{AR}(2)$ with coefficients $\theta_{1}$ and $\theta_{2}$, we have $\operatorname{Corr}\left(\pi_{t}, \pi_{t-1}\right)=\theta_{1} /\left(1-\theta_{2}\right)$. Thus, both measures of persistence are increasing in $\theta_{1}$ and $\theta_{2}$.
} 


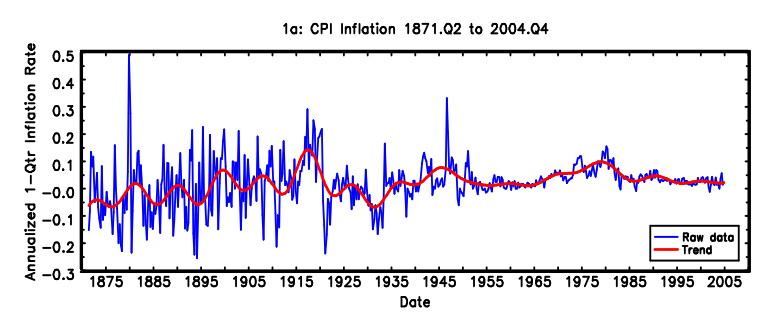

1c: Persistence of CPI Inflation

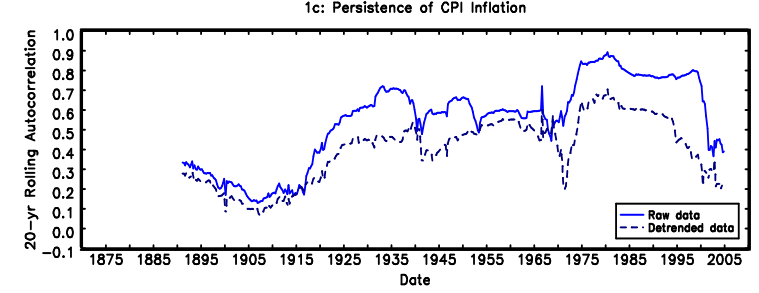

1e: Volatility of CPI Inflation

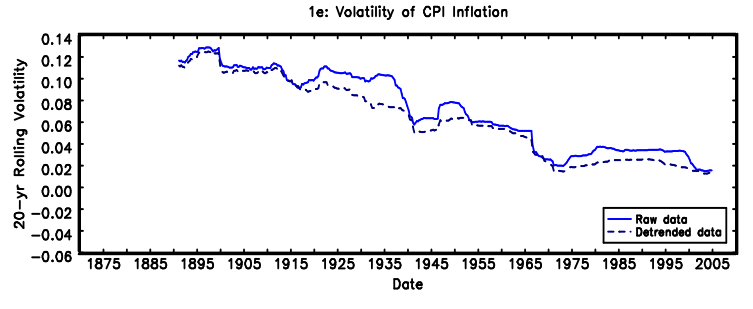

19: Mean of CPI Inflation

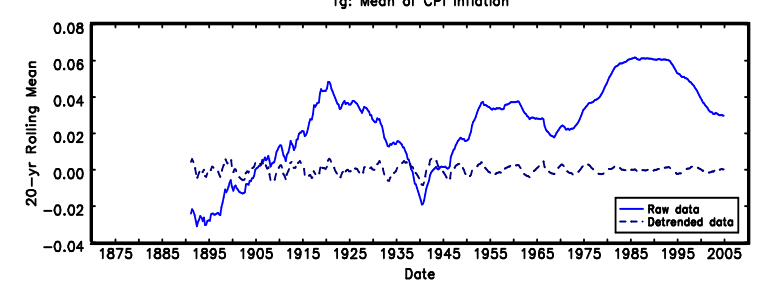

1b: GDP Price Inflation 1949.01 to 2004.04

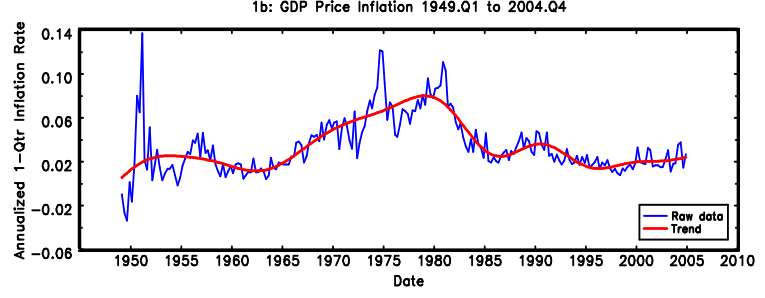

1d: Persistence of GDP Price Inflation

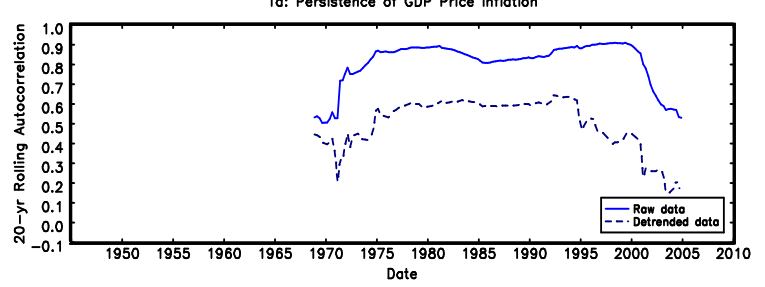

1f: Volatility of GDP Price Inflation

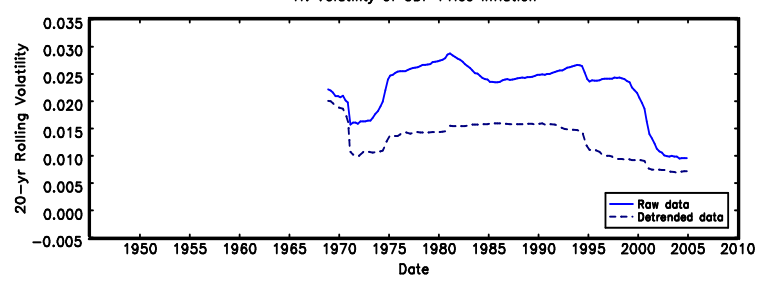

1h: Mean of GDP Price Inflation

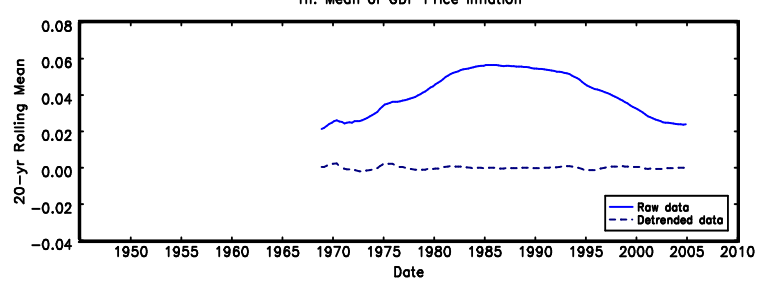

Figure 1: Long-run U.S. inflation data and 20-year rolling summary statistics

Volatility is measured by the 20-year rolling standard deviation. The volatility of CPI inflation declines steadily from the early part of the sample until about the year 1970. Volatility then traces out a hump-shaped pattern over the next 35 years (panel 1e). The volatility of GDP price inflation exhibits a similar hump-shaped pattern (panel 1f).

Measures of persistence and volatility are generally lower in the detrended data, but the basic patterns resemble those in the raw data. Notice that these measures have declined during the sample period since 1995. During the post-World War II sample period, the most striking feature is the similarity in the patterns observed for the rolling persistence, rolling volatility, and rolling mean of U.S. inflation. This result confirms the findings of Cogley and Sargent $(2001,2005)$ who use forward-looking Bayesian methods to identify a strong positive correlation among summary statistics computed for post-World War II inflation data. Interestingly, one can identify some roughly similar patterns of comovement in the rolling summary statistics for the earlier inflation data plotted on the left-side of Figure 1.

Although not plotted, both U.S. inflation series exhibit time-varying patterns of skewness and kurtosis. Over the full sample, U.S. inflation exhibits positive skewness and excess kurtosis, 
particularly in the detrended data. Overall, the time-varying and non-Gaussian features of the data indicate the presence of nonlinearities in the law of motion for U.S. inflation. In later sections of the paper, a complete quantitative summary of U.S. inflation dynamics will be compared with the results of model simulations.

\section{The New Keynesian Phillips Curve}

The starting point for the analysis is the standard NKPC:

$$
\pi_{t}=\beta \widehat{E}_{t} \pi_{t+1}+\gamma y_{t}+\varepsilon_{t}, \quad \beta \in[0,1), \gamma>0, \varepsilon_{t} \sim N\left(0, \sigma_{\varepsilon}^{2}\right),
$$

where $\pi_{t}$ is the inflation rate defined as the log difference of the price level, $\beta$ is the representative agent's subjective time discount factor, $y_{t}$ is a stationary driving variable, and $\varepsilon_{t}$ is an iid markup shock that is often motivated by the presence of a variable tax rate. ${ }^{7}$ The symbol $\widehat{E}_{t}$ represents the agent's subjective expectation conditioned on information available at time $t$. Under rational expectations, $\widehat{E}_{t}$ corresponds to the mathematical expectation operator $E_{t}$ evaluated using the objective distributions of the driving variable and the markup shock.

The driving variable can be interpreted as either the output gap (often measured by detrended real GDP) or the representative firm's real marginal cost (often measured by labor's share of income). Since $y_{t}$ is taken here to be exogenous, none of the paper's theoretical results depend on which interpretation is chosen. ${ }^{8}$ The law of motion for the driving variable is

$$
y_{t}=\rho y_{t-1}+u_{t} \quad \rho \in[0,1), \quad u_{t} \sim N\left(0, \sigma_{u}^{2}\right),
$$

where $u_{t}$ is an iid demand shock that is uncorrelated with the markup shock. Monetary policy enters implicitly in the model through two potential channels. The first is via the trend (or steady-state) inflation rate that is assumed when deriving equation (1) using a loglinear approximation. The second is via the values of $\rho$ and $\sigma_{u}^{2}$, which can be interpreted as reduced-form parameters that depend in a complicated way on the central bank's policy rule. ${ }^{9}$ Throughout the analysis, the trend inflation rate is assumed to be zero and the policydependent parameters $\rho$ and $\sigma_{u}^{2}$ are held constant.

\subsection{Rational Expectations}

Under rational expectations, the inflation rate at time $t$ is uniquely pinned down by the agent's forecast of discounted future values of the driving variable, plus the current realization of the markup shock. Two crucial assumptions are: (i) the agent knows the law of motion of the driving variable, and (ii) the agent can observe the markup shock. To derive the unique

\footnotetext{
${ }^{7}$ A complete derivation of equation (1) from first principles can be found in Woodford (2003, Chapter 3).

${ }^{8}$ In empirical applications, the choice of driving variable is quite important. Detrended real GDP is procyclical whereas labor's share of income is countercyclical. See Rudd and Whelan (2005c).

${ }^{9} \mathrm{~A}$ simple example illustrates the point. Suppose that the IS equation is given by $y_{t}=\alpha_{y} y_{t-1}-$ $\alpha_{r}\left(i_{i}-\widehat{E_{t}} \pi_{t+1}-\bar{r}\right)+\varsigma_{t}$, and the central bank's policy rule is given by $i_{t}=\bar{r}+g_{\pi} \widehat{E}_{t} \pi_{t+1}+g_{y} y_{t}$, where $i_{t}$ is the policy instrument, $\bar{r}$ is the steady-state real rate, and $\varsigma_{t}$ is an iid demand shock. Then, under rational expectations $\left(\widehat{E}_{t}=E_{t}\right)$, it can be shown that the equilibrum IS equation is exactly the form of $(2)$, where $\rho$ and $\sigma_{u}^{2}$ both depend on $g_{\pi}$ and $g_{y}$. If expectations are only boundedly-rational, then equation (2) is still likely to be reasonable approximation of an empirically-plausible IS equation.
} 
rational expectations solution, we first replace $\widehat{E}_{t}$ in equation (1) with the mathematical expectation operator $E_{t}$. Equation (1) can then be iterated forward to substitute out $\pi_{t+1+k}$ for $k=0,1,2, \ldots$ Applying the law of iterated expectations and imposing a transversality condition yields the following present-value inflation equation

$$
\begin{aligned}
\pi_{t}^{\mathrm{re}} & =\gamma E_{t}\left\{y_{t}+\beta y_{t+1}+\beta^{2} y_{t+2}+\ldots\right\}+\varepsilon_{t}, \\
& =\gamma E_{t}\left\{\sum_{i=t}^{\infty} \beta^{i-t} y_{i}\right\}+\varepsilon_{t},
\end{aligned}
$$

where $\pi_{t}^{\text {re }}$ represents the equilibrium inflation rate under rational expectations. Given that $u_{t}$ is iid, equation (3) admits the following closed-form solution:

$$
\pi_{t}^{\mathrm{re}}=\left[\frac{\gamma}{1-\rho \beta}\right] y_{t}+\varepsilon_{t}
$$

which shows that the rational (or fundamentals-based) inflation rate inherits its stochastic properties from both the autoregressive driving variable $y_{t}$ and the white-noise markup shock $\varepsilon_{t}$. The unconditional variance of $y_{t}$ from equation (2) is $\operatorname{Var}\left(y_{t}\right)=\sigma_{u}^{2} /\left(1-\rho^{2}\right)$. The unconditional variance of $\varepsilon_{t}$ is $\sigma_{\varepsilon}^{2}$. Fuhrer (2005) shows that empirically plausible values for the Phillips curve slope parameter $\gamma$ and the shock variance ratio $\sigma_{\varepsilon}^{2} / \sigma_{u}^{2}$ imply that the behavior of $\pi_{t}^{\mathrm{re}}$ more-closely resembles white noise - a result that conflicts sharply with post-World War II U.S. inflation data.

Equations (2) and (4) yield the following expressions for the unconditional moments:

$$
\begin{aligned}
\operatorname{Var}\left(\pi_{t}^{\mathrm{re}}\right) & =\left[\frac{\gamma^{2}}{(1-\rho \beta)^{2}\left(1-\rho^{2}\right)}\right] \sigma_{u}^{2}+\sigma_{\varepsilon}^{2}, \\
\operatorname{Corr}\left(\pi_{t}^{\mathrm{re}}, \pi_{t-1}^{\mathrm{re}}\right) & =\frac{\gamma^{2} \rho}{\gamma^{2}+(1-\rho \beta)^{2}\left(1-\rho^{2}\right)\left(\sigma_{\varepsilon}^{2} / \sigma_{u}^{2}\right)}, \\
\operatorname{Cov}\left(\Delta \pi_{t}^{\mathrm{re}}, y_{t}\right) & =\left[\frac{\gamma}{(1-\rho \beta)(1+\rho)}\right] \sigma_{u}^{2}, \\
\operatorname{Cov}\left(\Delta \pi_{t}^{\mathrm{re}}, y_{t-1}\right) & =-\left[\frac{\gamma}{(1-\rho \beta)(1+\rho)}\right] \sigma_{u}^{2}, \\
\operatorname{Var}\left(\Delta \pi_{t}^{\mathrm{re}}\right) & =\left[\frac{2 \gamma^{2}}{(1-\rho \beta)^{2}(1+\rho)}\right] \sigma_{u}^{2}+2 \sigma_{\varepsilon}^{2} \\
\operatorname{Cov}\left(\Delta \pi_{t}^{\mathrm{re}}, \Delta \pi_{t-1}^{\mathrm{re}}\right) & =-\left[\frac{\gamma^{2}(1-\rho)}{(1-\rho \beta)^{2}(1+\rho)}\right] \sigma_{u}^{2}-\sigma_{\varepsilon}^{2}
\end{aligned}
$$

where $\operatorname{Var}(\cdot)$ and $\operatorname{Cov}(\cdot, \cdot)$ denote the unconditional variance and covariance, respectively, $\operatorname{Corr}(\cdot, \cdot)$ is the unconditional correlation coefficient, and $\Delta \pi_{t}^{\mathrm{re}}=\pi_{t}^{\mathrm{re}}-\pi_{t-1}^{\mathrm{re}}$.

Equation (6) confirms the results of Fuhrer (2005) that small values for the Phillips curve slope parameter $\gamma$ combined with nontrivial values for the shock variance ratio $\sigma_{\varepsilon}^{2} / \sigma_{u}^{2}$ (the empirically plausible case) imply very weak persistence of inflation under rational expectations. Equations (7) and (8) predict that the first difference of inflation covaries positively with the current value of the driving variable but covaries negatively with its lagged value. The latter prediction is not consistent with U.S. data when the driving variable is measured by 
detrended real GDP. Finally, dividing equation (10) by equation (9) yields the prediction that the autocorrelation of inflation changes is negative - a robust feature of U.S. data.

From equation (4), the one-period-ahead rational forecast is given by

$$
E_{t} \pi_{t+1}^{\mathrm{re}}=\left[\frac{\gamma \rho}{1-\rho \beta}\right] y_{t}
$$

which requires information about the current value of $y_{t}$, the policy-dependent parameter $\rho$, and the Phillips curve slope parameter $\gamma$. The discount factor $\beta$ is aspect of the agent's preferences and hence does not need to be observed.

\subsection{Consistent Expectations}

Equation (11) shows that rational forecasts derived from the standard NKPC are built on strong assumptions about the representative agent's information set. In actual forecasting applications, real-time difficulties in observing the driving variable $y_{t}$, together with empirical instabilities in the parameters $\gamma$ and $\rho$, could lead to large and persistent forecast errors. Numerous studies have demonstrated that forecasts of U.S. inflation computed from backward-looking Phillips curve models can frequently underperform forecasts derived from simple univariate time series models, such as a random walk, AR, or ARMA. ${ }^{10}$ One would expect to encounter similar forecasting difficulties using the standard NKPC. These ideas motivate consideration of alternative forecasting algorithm - one that requires less computational and informational resources. A long history in macroeconomics suggests the following error-correction approach:

$$
\begin{aligned}
\widehat{E}_{t} \pi_{t+1} & =\widehat{E}_{t-1} \pi_{t}+\lambda\left(\pi_{t}-\widehat{E}_{t-1} \pi_{t}\right), \quad 0<\lambda \leq 1 \\
& =\lambda\left[\pi_{t}+(1-\lambda) \pi_{t-1}+(1-\lambda)^{2} \pi_{t-2}+\ldots\right]
\end{aligned}
$$

where $\pi_{t}-\widehat{E}_{t-1} \pi_{t}$ is the forecast error in period $t$. Equation (12) is immediately recognizable as adaptive expectations. I assume here that the adaptive forecast makes use of the contemporaneous realization $\pi_{t}$. This setup avoids the introduction of an extra lag of inflation that might be viewed as artificially influencing the resulting dynamics. ${ }^{11}$ Equation (12) implies that the agent's subjective forecast at time $t$ is determined by an exponentially-weighted moving average of past observed inflation rates. By comparison, the "sticky-information" model of Mankiw and Reis (2002) implies that the agent's subjective forecast at time $t$ is based on an exponentially-weighted moving average of past rational forecasts. ${ }^{12}$ Both arrangements bear symmetry to the Calvo (1983) sticky-price model where the equilibrium price level at time $t$ is an exponentially-weighted moving average of past observed prices.

\footnotetext{
${ }^{10}$ See, for example, Atkeson and Ohanian (2001), Stock and Watson (2005), Orphanides and Van Norden (2005), and Ang. et al. (2005).

${ }^{11}$ A lagged information assumption is often used in learning models to avoid simultaneity in the determination of the actual and expected values of the forecast variable. In the continuous time limit, the distinction between contemporaneous and lagged information disappears.

${ }^{12}$ As shown by Carroll (2003), a simplified version of the Mankiw-Reis setup can be written as $\widehat{E}_{t} \pi_{t+1}=$ $\widehat{E}_{t-1} \pi_{t}+\mu\left(E_{t} \pi_{t+1}-\widehat{E}_{t-1} \pi_{t}\right)$, where $\mu$ is an exogenously-determined parameter that represents the fraction of agents who update to the rational forecast $E_{t} \pi_{t+1}$ each period.
} 
As originally shown by Muth (1960), adaptive expectations will coincide with rational expectations when the forecast variable follows a simple and intuitive law of motion. That form is adopted here as the representative agent's perceived law of motion:

$$
\left[\begin{array}{l}
\pi_{t} \\
\bar{\pi}_{t}
\end{array}\right]=\left[\begin{array}{ll}
0 & 1 \\
0 & 1
\end{array}\right]\left[\begin{array}{l}
\pi_{t-1} \\
\bar{\pi}_{t-1}
\end{array}\right]+\left[\begin{array}{ll}
1 & 1 \\
0 & 1
\end{array}\right]\left[\begin{array}{l}
v_{t} \\
\eta_{t}
\end{array}\right], \quad \begin{aligned}
& v_{t} \sim N\left(0, \sigma_{v}^{2}\right) \\
& \eta_{t} \sim N\left(0, \sigma_{\eta}^{2}\right) \\
& \operatorname{Cov}\left(v_{t}, \eta_{t}\right)=0
\end{aligned}
$$

where $\bar{\pi}_{t}$ is the central bank's unobservable inflation target which determines the inflation trend, $v_{t}$ is a transitory shock that pushes $\pi_{t}$ away from the target, and $\eta_{t}$ is permanent shock (presumed to be uncorrelated with $v_{t}$ ) that shifts the inflation target over time. The agent's subjective forecast $\widehat{E}_{t} \pi_{t+1}$ is set equal to the Kalman filter estimate of $\bar{\pi}_{t}$. The random walk plus noise specification in (13) is equivalent to an ARMA (1,1), as shown by Harvey (1993, p. 125). From the agent's perspective, this would appear to be a reasonable candidate law of motion because: (i) it allows for permanent shifts in the inflation target, and (ii) it can account for historical episodes where inflation has evolved along a seemingly non-stationary trajectory.

As evidence of the reasonableness of the agent's perceived law of motion, it is worth considering some recent examples from the literature. In the model of Erceg and Levin (2003), the Fed's inflation target follows an AR(1) process with a coefficient of 0.999. Kozicki and Tinsely (2005) model the Fed's inflation target as a random walk process augmented with a dummy variable that allows for a discrete downward shift in 1979.Q4. Ireland (2006) adopts a geometric random walk specification for the Fed's inflation target. His estimated inflation target series for the period 1959.Q1 to 2004.Q2 closely resembles the low-frequency component of U.S. inflation plotted in Figure 1. Lastly, in the empirical model of Piger and Rasche (2006), the estimated law of motion for inflation includes a random walk component that is interpreted as a measure of long-horizon inflation expectations.

The agent's perceived optimal choice of $\lambda$ in equation (12) is determined by the Kalman filter as the solution to a signal extraction problem where the objective is to minimize the mean squared forecast error. In steady-state, the unique solution for the optimal gain parameter is

$$
\lambda=\frac{-\phi+\sqrt{\phi^{2}+4 \phi}}{2}
$$

where $\phi=\sigma_{\eta}^{2} / \sigma_{v}^{2}$ is the signal-to-noise ratio. ${ }^{13}$ As $\phi \rightarrow \infty$, the gain parameter approaches 1 . From the agent's perspective, the shocks $v_{t}$ and $\eta_{t}$ are unobservable, but the value of $\phi$ can be inferred from the moments of inflation changes $\Delta \pi_{t}$, which are observable.

Proposition 1. If the representative agent's perceived law of motion is given by equation (13), then the perceived optimal value of the gain parameter $\lambda$ is uniquely pinned down by the autocorrelation of observed inflation changes, $\operatorname{Corr}\left(\Delta \pi_{t}, \Delta \pi_{t-1}\right)$.

Proof: From (13), we have $\Delta \pi_{t}=\eta_{t}+v_{t}-v_{t-1}$. Since $\eta_{t}$ and $v_{t}$ are perceived to be independent, we have $\operatorname{Cov}\left(\Delta \pi_{t}, \Delta \pi_{t-1}\right)=-\sigma_{v}^{2}$ and $\operatorname{Var}\left(\Delta \pi_{t}\right)=\sigma_{\eta}^{2}+2 \sigma_{v}^{2}$. Combining these two expressions and solving for the signal-to-noise ratio yields

$$
\phi=\frac{-1}{\operatorname{Corr}\left(\Delta \pi_{t}, \Delta \pi_{t-1}\right)}-2,
$$

\footnotetext{
${ }^{13}$ For details, see Harvey (1993), pp. 126-127.
} 
where $\phi=\sigma_{\eta}^{2} / \sigma_{v}^{2}$ and $\operatorname{Corr}\left(\Delta \pi_{t}, \Delta \pi_{t-1}\right)=\operatorname{Cov}\left(\Delta \pi_{t}, \Delta \pi_{t-1}\right) / \operatorname{Var}\left(\Delta \pi_{t}\right)$. The above expression shows that $\operatorname{Corr}\left(\Delta \pi_{t}, \Delta \pi_{t-1}\right)$ uniquely pins down $\phi$ which, in turn, uniquely pins down $\lambda$ from equation (14).

Substituting the agent's perceived optimal forecast (12) into the NKPC equation (1) yields the following system of equations that define the actual law of motion for inflation:

$$
\left[\begin{array}{c}
\pi_{t} \\
\widehat{E}_{t} \pi_{t+1} \\
y_{t}
\end{array}\right]=\underbrace{\left[\begin{array}{ccc}
0 & \frac{\beta(1-\lambda)}{1-\beta \lambda} & \frac{\gamma \rho}{1-\beta \lambda} \\
0 & \frac{1-\lambda}{1-\beta \lambda} & \frac{\gamma \rho \lambda}{1-\beta \lambda} \\
0 & 0 & \rho
\end{array}\right]}_{\mathbf{A}}\left[\begin{array}{c}
\pi_{t-1} \\
\widehat{E}_{t-1} \pi_{t} \\
y_{t-1}
\end{array}\right]+\underbrace{\left[\begin{array}{cc}
\frac{\gamma}{1-\beta \lambda} & \frac{1}{1-\beta \lambda} \\
\frac{\gamma \lambda}{1-\beta \lambda} & \frac{\lambda}{1-\beta \lambda} \\
1 & 0
\end{array}\right]}_{\mathbf{B}}\left[\begin{array}{c}
u_{t} \\
\varepsilon_{t}
\end{array}\right],
$$

where $\lambda$ appears in numerous coefficients. The variance-covariance matrix $\mathbf{V}$ of the left-side variables in equation (15) can be computed using the formula:

$$
\operatorname{vec}(\mathbf{V})=[\mathbf{I}-\mathbf{A} \otimes \mathbf{A}]^{-1} \operatorname{vec}\left(\mathbf{B} \boldsymbol{\Omega} \mathbf{B}^{\prime}\right),
$$

where $\Omega$ is the variance-covariance matrix of the fundamental shocks $\varepsilon_{t}$ and $u_{t}$. Since the matrix A contains only five non-zero elements, straightforward (but tedious) computations yield the following analytical expressions for the unconditional moments:

$$
\begin{aligned}
\operatorname{Var}\left(\widehat{E}_{t} \pi_{t+1}\right)= & {\left[\frac{1-\beta \lambda+\rho(1-\lambda)}{1-\beta \lambda-\rho(1-\lambda)}\right]\left\{\frac{\gamma^{2} \lambda^{2}}{\left[(1-\beta \lambda)^{2}-(1-\lambda)^{2}\right]\left(1-\rho^{2}\right)}\right\} \sigma_{u}^{2} } \\
& +\left[\frac{\lambda^{2}}{(1-\beta \lambda)^{2}-(1-\lambda)^{2}}\right] \sigma_{\varepsilon}^{2} \\
\operatorname{Var}\left(\pi_{t}\right)= & {\left[\frac{\gamma^{2}}{(1-\beta \lambda)^{2}\left(1-\rho^{2}\right)}\right]\left[1+\frac{2 \beta \rho \lambda(1-\lambda)}{1-\beta \lambda-\rho(1-\lambda)}\right] \sigma_{u}^{2} } \\
& +\left[\frac{1}{(1-\beta \lambda)^{2}}\right] \sigma_{\varepsilon}^{2}+\left[\frac{\beta^{2}(1-\lambda)^{2}}{(1-\beta \lambda)^{2}}\right] \operatorname{Var}\left(\widehat{E}_{t} \pi_{t+1}\right), \\
\operatorname{Cov}\left(\pi_{t}, \pi_{t-1}\right)= & {\left[\frac{\gamma^{2}}{(1-\beta \lambda)^{2}\left(1-\rho^{2}\right)}\right]\left\{\rho+\left[\frac{\beta \lambda(1-\lambda)}{(1-\beta \lambda)}\right]\left[\frac{\rho \beta(1-\lambda)+\left(1+\rho^{2}\right)(1-\beta \lambda)}{1-\beta \lambda-\rho(1-\lambda)}\right]\right\} \sigma_{u}^{2} } \\
& +\left[\frac{\beta \lambda(1-\lambda)}{(1-\beta \lambda)^{3}}\right] \sigma_{\varepsilon}^{2}+\left[\frac{\beta^{2}(1-\lambda)^{3}}{(1-\beta \lambda)^{3}}\right] \operatorname{Var}\left(\widehat{E}_{t} \pi_{t+1}\right), \\
\operatorname{Cov}\left(\Delta \pi_{t}, y_{t}\right)= & \left\{\frac{\gamma[1-\rho(1-\lambda)]}{[1-\beta \lambda-\rho(1-\lambda)](1+\rho)}\right\} \sigma_{u}^{2}, \\
\operatorname{Cov}\left(\Delta \pi_{t}, y_{t-1}\right)= & {\left[\frac{\gamma}{(1-\beta \lambda)(1+\rho)}\right]\left[\frac{\beta \lambda(1-\lambda)}{1-\beta \lambda-\rho(1-\lambda)}-1\right] \sigma_{u}^{2}, }
\end{aligned}
$$

which are all nonlinear in the gain parameter $\lambda$. From equation (19), we see that inflation persistence is always positive, but the precise magnitude depends on the value of $\lambda$ and several other parameters. For values of $\rho$ and $\beta$ near one (the empirically plausible case), equations (20) and (21) show that the first difference of inflation covaries positively with both the current value and lagged value of the driving variable. This feature is consistent with U.S. data when the driving variable is measured by detrended real GDP. Recall that under rationalexpectations, the NKPC predicts a positive covariance with the current value of the driving variable, but a negative covariance with the lagged value. 


\subsubsection{Defining the Consistent Expectations Equilibrium}

This section defines the concept of a "consistent expectations equilibrium" along the lines of Hommes and Sorger (1998). By applying the results of Proposition 1, the value of the gain parameter $\lambda$ that appears in the adaptive forecast rule (12) can be uniquely pinned down using the correlation structure of the observed time series. Since the agent's perceived law of motion (13) implies that $\pi_{t}$ is nonstationary, it is natural to assume that the agent's forecast rule is parameterized to match the autocorrelation of $\Delta \pi_{t} \cdot{ }^{14}$ The following expression for $\Delta \pi_{t}$ can be derived from the actual law of motion (15):

$$
\begin{aligned}
\Delta \pi_{t}= & \underbrace{\left[\frac{\gamma}{1-\beta \lambda}\right]}_{a_{u}} u_{t}+\underbrace{\left[\frac{\gamma}{1-\beta \lambda}\right]\left[\frac{\beta \lambda(1-\lambda)}{1-\beta \lambda}+\rho-1\right]}_{b_{u}} u_{t-1} \\
& +\underbrace{\left[\frac{1}{1-\beta \lambda}\right]}_{a_{\varepsilon}} \varepsilon_{t}+\underbrace{\left[\frac{1}{1-\beta \lambda}\right]\left[\frac{\beta \lambda(1-\lambda)}{1-\beta \lambda}-1\right]}_{b_{\varepsilon}} \varepsilon_{t-1} \\
& +\underbrace{\left[\frac{-\beta \lambda(1-\lambda)(1-\beta)}{(1-\beta \lambda)^{2}}\right]}_{a_{\pi}} \widehat{E}_{t-2} \pi_{t-1}+\underbrace{\left[\frac{\gamma \rho}{1-\beta \lambda}\right]\left[\frac{\beta \lambda(1-\lambda)}{1-\beta \lambda}+\rho-1\right]}_{a_{y}} y_{t-2},
\end{aligned}
$$

where the constants $a_{i}$ and $b_{i}$ are used here to represent combinations of parameters. Equation (22) can be used to compute the following unconditional moments:

$$
\begin{aligned}
\operatorname{Var}\left(\Delta \pi_{t}\right)= & {\left[a_{u}^{2}+b_{u}^{2}+\frac{a_{y}^{2}}{\left(1-\rho^{2}\right)}\right] \sigma_{u}^{2}+\left(a_{\varepsilon}^{2}+b_{\varepsilon}^{2}\right) \sigma_{\varepsilon}^{2} } \\
& +a_{\pi}^{2} \operatorname{Var}\left(\widehat{E}_{t} \pi_{t+1}\right)+2 a_{\pi} a_{y} \operatorname{Cov}\left(\widehat{E}_{t} \pi_{t+1}, y_{t}\right) \\
\operatorname{Cov}\left(\Delta \pi_{t}, \Delta \pi_{t-1}\right)= & \left\{b_{u}\left[a_{u}+a_{y}+\frac{a_{\pi} \gamma \lambda}{1-\beta \lambda}\right]+\frac{\rho}{1-\rho^{2}}\left[a_{y}^{2}+\frac{a_{\pi} a_{y} \gamma \lambda}{1-\beta \lambda}\right]\right\} \sigma_{u}^{2} \\
& +b_{\varepsilon}\left[a_{\varepsilon}+\frac{a_{\pi} \lambda}{1-\beta \lambda}\right] \sigma_{\varepsilon}^{2}+\frac{a_{\pi}^{2}(1-\lambda)}{1-\beta \lambda} \operatorname{Var}\left(\widehat{E}_{t} \pi_{t+1}\right) \\
& +\left[\frac{a_{\pi}^{2} \gamma \rho \lambda}{1-\beta \lambda}+a_{\pi} a_{y}\left(\frac{1-\lambda}{1-\beta \lambda}+\rho\right)\right] \operatorname{Cov}\left(\widehat{E}_{t} \pi_{t+1}, y_{t}\right),
\end{aligned}
$$

where $\operatorname{Var}\left(\widehat{E}_{t} \pi_{t+1}\right)$ is given by equation (17) and the covariance between the agent's subjective forecast and the driving variable is given by:

$$
\operatorname{Cov}\left(\widehat{E}_{t} \pi_{t+1}, y_{t}\right)=\left\{\frac{\gamma \lambda}{\left[(1-\beta \lambda)^{2}-(1-\lambda)^{2}\right]\left(1-\rho^{2}\right)}\right\} \sigma_{u}^{2} .
$$

Dividing equation (24) by equation (23) yields an expression for $\operatorname{Corr}\left(\Delta \pi_{t}, \Delta \pi_{t-1}\right)$ which is nonlinear in the gain parameter $\lambda$. This nonlinear expression is employed in the following definition of equilibrium.

\footnotetext{
${ }^{14}$ In Hommes and Sorger (1998), the agent's forecast rule is parameterized for a perceived law of motion that is linear, when in fact the actual law of motion is nonlinear. Here, the agent's forecast rule is parameterized for a perceived law of motion that is nonstationary, when in fact the actual law of motion is stationary (but highly persistent).
} 
Definition 1. A consistent expectations equilibrium is defined as a perceived law of motion (13), an actual law of motion (15), and an associated gain parameter $\lambda$, such that $\lambda$ is the fixed point of the nonlinear map $\lambda=f(\lambda)$, where

$$
\begin{aligned}
& f(\lambda)=\frac{-\phi(\lambda)+\sqrt{\phi(\lambda)^{2}+4 \phi(\lambda)}}{2}, \\
& \phi(\lambda)=\frac{-1}{\operatorname{Corr}\left(\Delta \pi_{t}, \Delta \pi_{t-1}\right)}-2=\frac{-\operatorname{Var}\left(\Delta \pi_{t}\right)}{\operatorname{Cov}\left(\Delta \pi_{t}, \Delta \pi_{t-1}\right)}-2,
\end{aligned}
$$

with $\operatorname{Var}\left(\Delta \pi_{t}\right)$ and $\operatorname{Cov}\left(\Delta \pi_{t}, \Delta \pi_{t-1}\right)$ computed from the actual law of motion, as given by equations (23) and (24).

\section{Numerical Solution for the Equilibrium}

The complexity of the nonlinear map $\lambda=f(\lambda)$ necessitates a numerical solution for the equilibrium. To accomplish this, the model is calibrated using a set of parameter values that are either estimated directly, or based on empirical estimates reported in the literature. The driving variable for inflation is assumed to be the output gap, i.e., the deviation of log real GDP from log potential output. ${ }^{15}$ Based on the results of 20-year rolling AR(1) regressions for the output gap over the period 1949.Q1 to 2004.Q4, I choose $\rho=0.90$ and $\sigma_{u}=0.01$. Estimates of the NKPC parameters $\beta, \gamma$, and $\sigma_{\varepsilon}$ are sensitive to the choice of the driving variable, the specification for inflation expectations, the sample period, and the econometric method. ${ }^{16}$ Based on the various studies, I choose $\beta=0.98, \gamma=0.03$, and $\sigma_{\varepsilon}=0.01$ as baseline values. I also examine the sensitivity of the results to some alternative parameter values.

Figure 2 plots $f(\lambda)$ over the admissible range $0<\lambda \leq 1$. For the baseline calibration with slope parameter $\gamma=0.03$, the unique fixed point occurs at $\lambda^{*}=0.346$ (panel 2a). When the slope parameter is increased to $\gamma=0.08$, the unique fixed point shifts upward to $\lambda^{*}=0.695$ (panel 2b). A higher value of $\lambda^{*}$ means that the representative agent is assigning more weight to recent inflation data because the perceived signal-to-noise ratio has increased. Experiments with the model show that $\lambda^{*}$ increases with the values of $\gamma, \rho, \sigma_{u}^{2}$, and $\beta$, but decreases with the value of $\sigma_{\varepsilon}^{2}$. These results are completely intuitive. Roughly speaking, parameter changes that increase the persistence of inflation via the driving variable $\left(\gamma, \rho\right.$, and $\left.\sigma_{u}^{2}\right)$ or via the expectations term $(\beta)$ have the effect of increasing the perceived signal-to-noise ratio. Parameter changes that decrease the persistence of inflation via the markup shock channel $\left(\sigma_{\varepsilon}^{2}\right)$ have the effect of decreasing the perceived signal-to-noise ratio. Finally, notice that the plot of $f(\lambda)$ lies very close to the 45-degree line for a wide range of candidate $\lambda$ values. This result suggests that forecast accuracy is not likely to suffer much as long as $\lambda$ remains in the general vicinity of $\lambda^{*}$. This conjecture turns out to be true, as discussed later in section 5 .

\footnotetext{
${ }^{15}$ Data on real GDP is from http://research.stlouisfed.org/fred2/series/GDPC96. The potential output series is constructed by the U.S. Congressional Budget Office. The data is available from http://research.stlouisfed.org/fred2/series/GDPPOT.mm

${ }^{16}$ See, for example, Roberts (2005), Rudd and Whelan (2005a, 2005b), Galí et al. (2005), Neiss and Nelson (2005), Fuhrer (2005), and Adam and Padula (2003).
} 
2a: Numerical Solution with $\gamma=0.03$

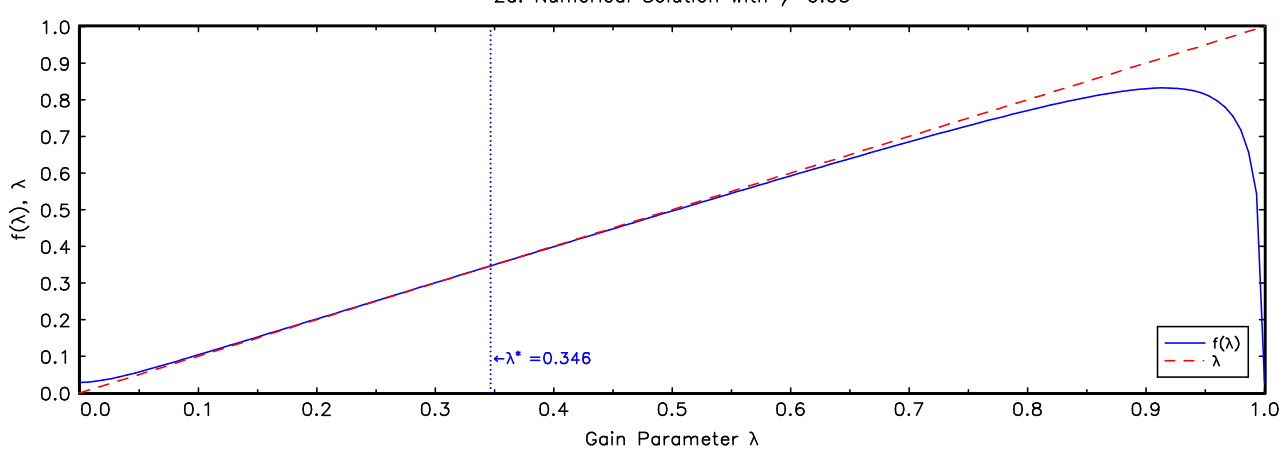

2a: Numerical Solution with $\gamma=0.08$

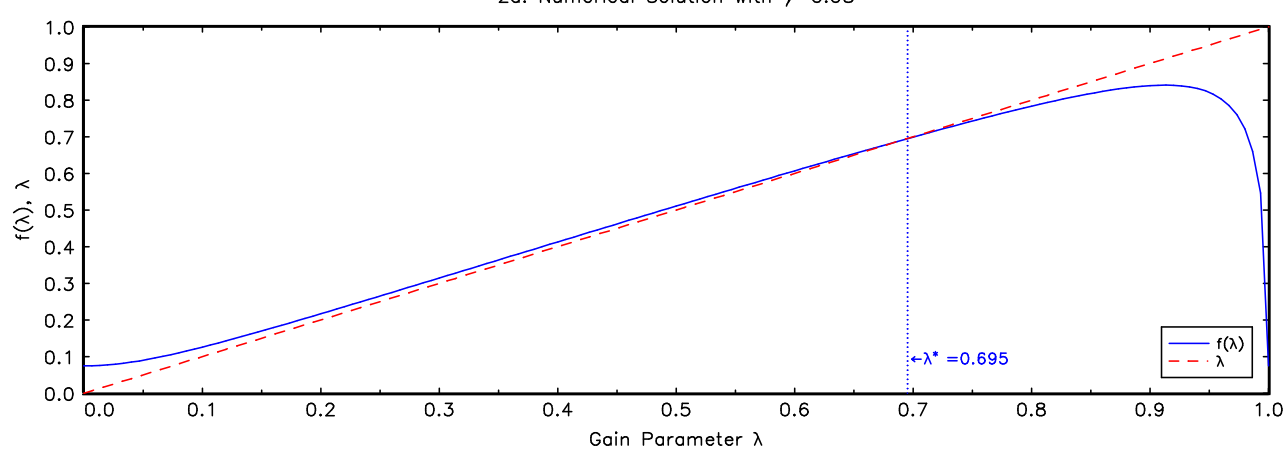

Figure 2: Determination of $\lambda^{*}$ for consistent expectations equilibrium.

Table 1: Sensitivity Analysis

\begin{tabular}{ccccc}
\hline \hline & & & & \\
Variance & & \multicolumn{3}{c}{ Phillips Curve Slope Parameter } \\
\cline { 3 - 5 } Ratio & Result & $\gamma=0.01$ & $\gamma=0.03$ & $\gamma=0.08$ \\
\hline & $\phi^{*}$ & 0.01 & 0.06 & 0.49 \\
$\sigma_{\varepsilon}^{2} / \sigma_{u}^{2}=3$ & $\lambda^{*}$ & 0.10 & 0.22 & 0.50 \\
& $\operatorname{Corr}\left(\pi_{t}, \pi_{t-1}\right)$ & 0.70 & 0.84 & 0.92 \\
& $\operatorname{Corr}\left(\pi_{t}^{\mathrm{re}}, \pi_{t-1}^{\mathrm{re}}\right)$ & 0.01 & 0.09 & 0.40 \\
\hline & $\phi^{*}$ & 0.01 & 0.09 & 0.77 \\
$\sigma_{\varepsilon}^{2} / \sigma_{u}^{2}=2$ & $\lambda^{*}$ & 0.11 & 0.26 & 0.57 \\
& $\operatorname{Corr}\left(\pi_{t}, \pi_{t-1}\right)$ & 0.73 & 0.87 & 0.93 \\
& $\operatorname{Corr}\left(\pi_{t}^{\mathrm{re}}, \pi_{t-1}^{\mathrm{re}}\right)$ & 0.02 & 0.13 & 0.49 \\
\hline & $\phi^{*}$ & 0.02 & 0.18 & 1.58 \\
$\sigma_{\varepsilon}^{2} / \sigma_{u}^{2}=1$ & $\lambda^{*}$ & 0.14 & 0.35 & 0.70 \\
& $\operatorname{Corr}\left(\pi_{t}, \pi_{t-1}\right)$ & 0.78 & 0.90 & 0.93 \\
& $\operatorname{Corr}\left(\pi_{t}^{\mathrm{re}}, \pi_{t-1}^{\mathrm{re}}\right)$ & 0.03 & 0.23 & 0.64 \\
\hline
\end{tabular}

Notes: Changes in $\sigma_{\varepsilon}^{2} / \sigma_{u}^{2}$ are accomplished by adjusting the markup shock variance $\sigma_{\varepsilon}^{2}$, with $\sigma_{u}^{2}=(0.01)^{2}$. Other parameters are held constant at the values: $\beta=0.98$, and $\rho=0.90$. 
3a: Inflation Persistence
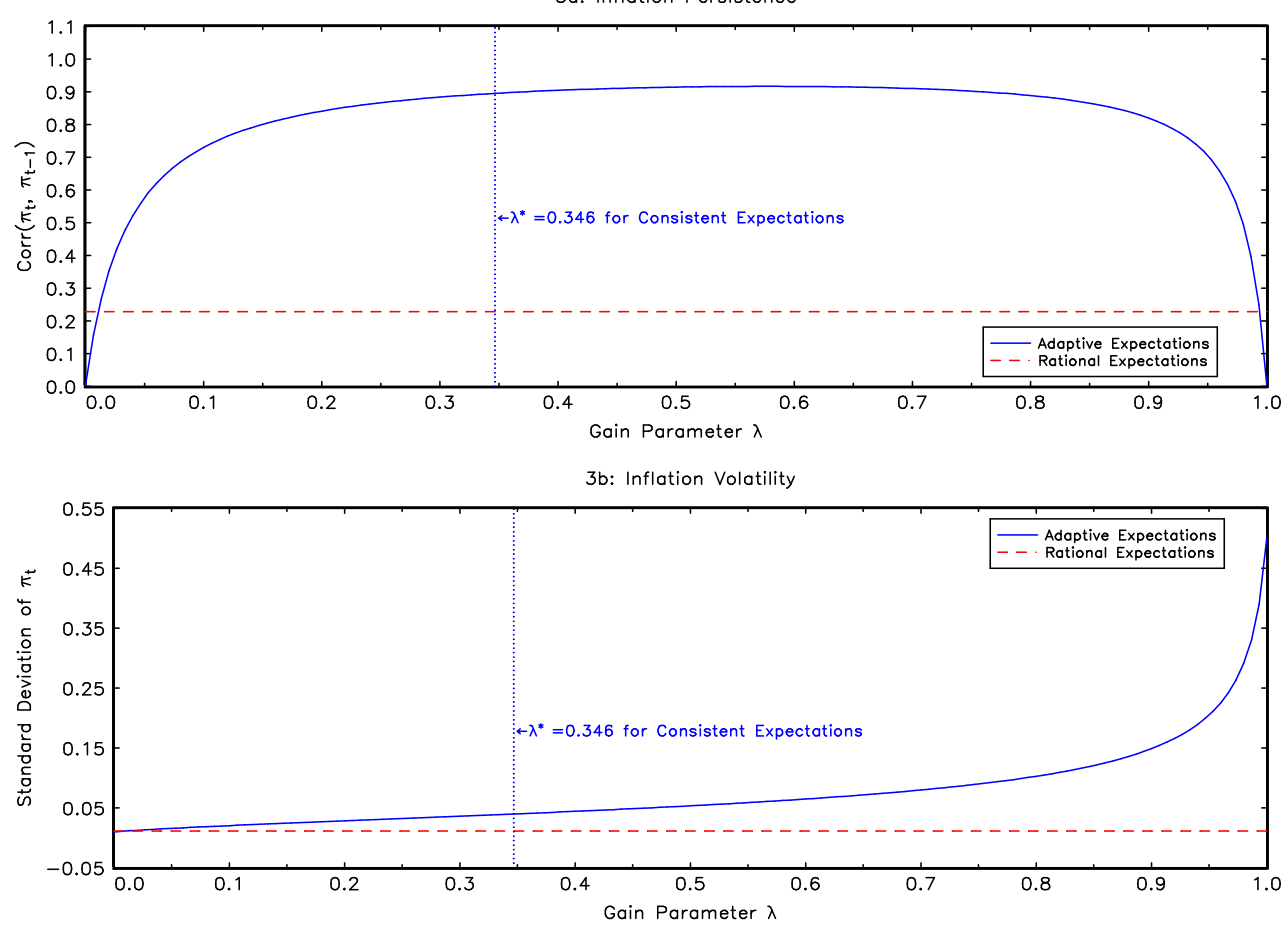

Figure 3: Inflation persistence and volatility under different forms of expectations.

Table 1 provides a sensitivity analysis to show how the equilibrium values of $\phi^{*}$ and $\lambda^{*}$ change with the slope parameter $\gamma$ and the fundamental shock variance ratio $\sigma_{\varepsilon}^{2} / \sigma_{u}^{2}$ The table also compares inflation persistence (as measured by the first-order autocorrelation) under the two forms of expectations: consistent versus rational. The table shows that $\phi^{*}$ and $\lambda^{*}$ are highest for parameter configurations at the bottom right, those with high $\gamma$ and low $\sigma_{\varepsilon}^{2} / \sigma_{u}^{2}$. Inflation persistence is also highest for these configurations. At the baseline calibration with $\gamma=0.03$ and $\sigma_{\varepsilon}^{2} / \sigma_{u}^{2}=1$, we have $\operatorname{Corr}\left(\pi_{t}, \pi_{t-1}\right)=0.90$ versus $\operatorname{Corr}\left(\pi_{t}^{\mathrm{re}}, \pi_{t-1}^{\mathrm{re}}\right)=0.23$.

Figure 3 shows how inflation persistence and volatility are influenced by the gain parameter. All parameters are set to their baseline values. The term "adaptive expectations" is used here to describe the general case where the value of $\lambda$ is not pinned down by any perceived optimal algorithm. The term "consistent expectations" is reserved for the special case when $\lambda=\lambda^{*}$. Panel 3a shows that inflation persistence is generally high under adaptive expectations, but drops off dramatically for $\lambda>0.9$ or $\lambda<0.1$. Panel 3b shows that inflation volatility increases with $\lambda$ in a nonlinear fashion and always exceeds the corresponding value under rational expectations. The fact that inflation persistence and volatility can vary, depending on the value of $\lambda$, is an important feature of the model that will be examined further in the quantitative simulations presented in section 6 . 
4a: Autocorrelation of Changes in U.S. GDP Price Inflation

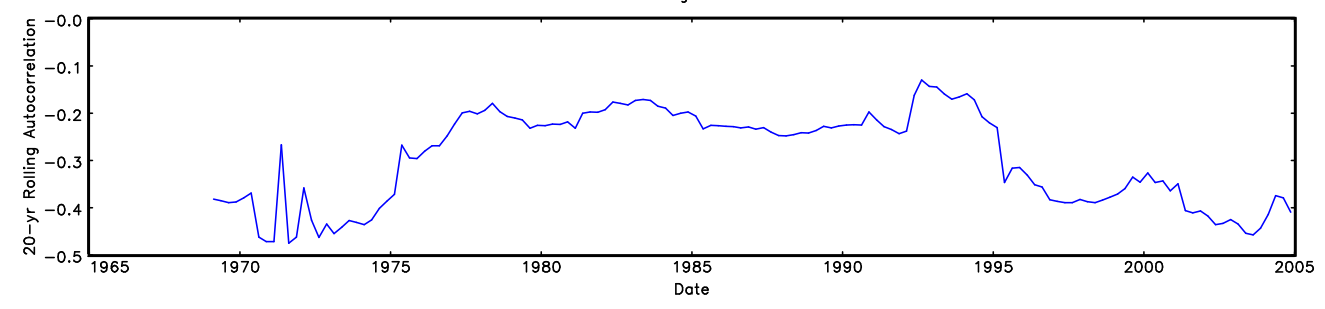

4b: Perceived Signal-to-Noise Ratio for U.S. GDP Price Inflation

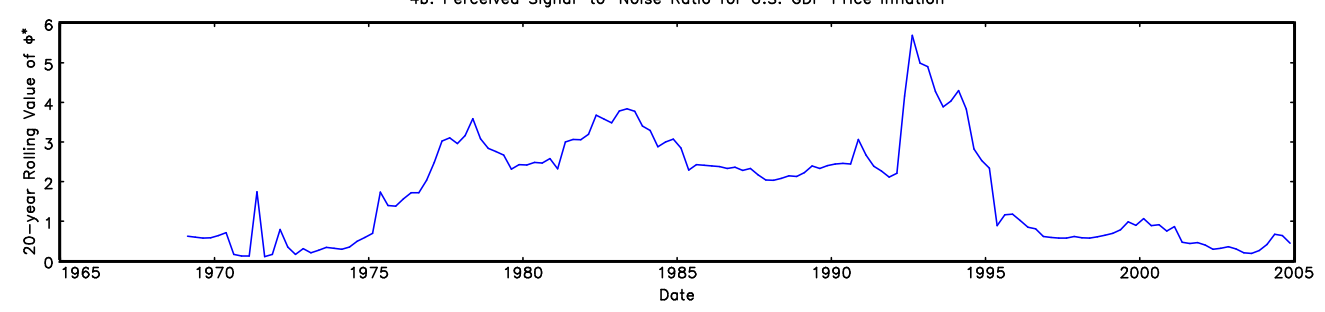

4c: Perceived Optimal Gain Parameter for U.S. GDP Price Inflation

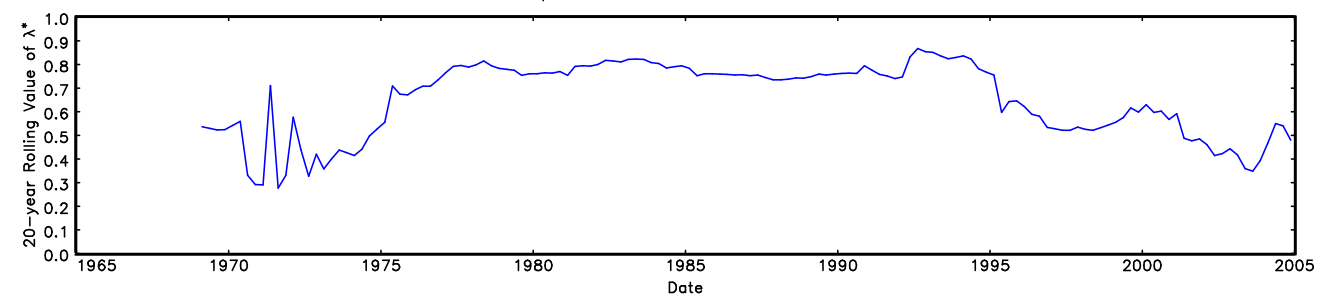

Figure 4: Identifying the signal-to-noise ratio and the optimal gain parameter from U.S. data.

\section{Applying the Model's Methodology to U.S. Inflation Data}

Figure 4 provides a check on the reasonableness of the equilibrium values of $\phi^{*}$ and $\lambda^{*}$ implied by the model. Panel 4a plots the 20-year rolling autocorrelation coefficient for the change in U.S. GDP price inflation. The autocorrelation coefficient is negative throughout the sample. Panel $4 \mathrm{~b}$ plots the perceived signal-to-noise ratio computed directly from the autocorrelation coefficient using the formula in Proposition 1. The perceived signal-to-noise ratio fluctuates from a low of 0.1 to a high of 5.7. The upward spike that occurs in the early-1990s is due to the autocorrelation coefficient becoming less negative at that time. The perceived ratio drifts upward in the 1970s, remains high for about two decades, and then drifts downward from the mid-1990s onwards. Stock and Watson (2005) obtain a similar humped-shaped pattern for the signal-to-noise ratio when estimating an unobserved-components model identical to (13) using quarterly data on U.S. GDP price inflation from 1953.Q1 to 2004.Q4. They identify statistically significant movements in the variance of the permanent shock, but cannot reject the hypothesis of no change in the variance of the transitory shock. Piger and Rasche (2006) report a decline in the estimated variance of permanent shocks to U.S. inflation in the sample period after 1994.Q1. They interpret their results as "evidence that long-horizon inflation expectations have become better anchored during the period of increasing FOMC transparency." The foregoing results suggest that the inverse of the signal-to-noise ratio identified from U.S. inflation data might be used as a quantitative measure of the Fed's credibility for maintaining a constant inflation target. 

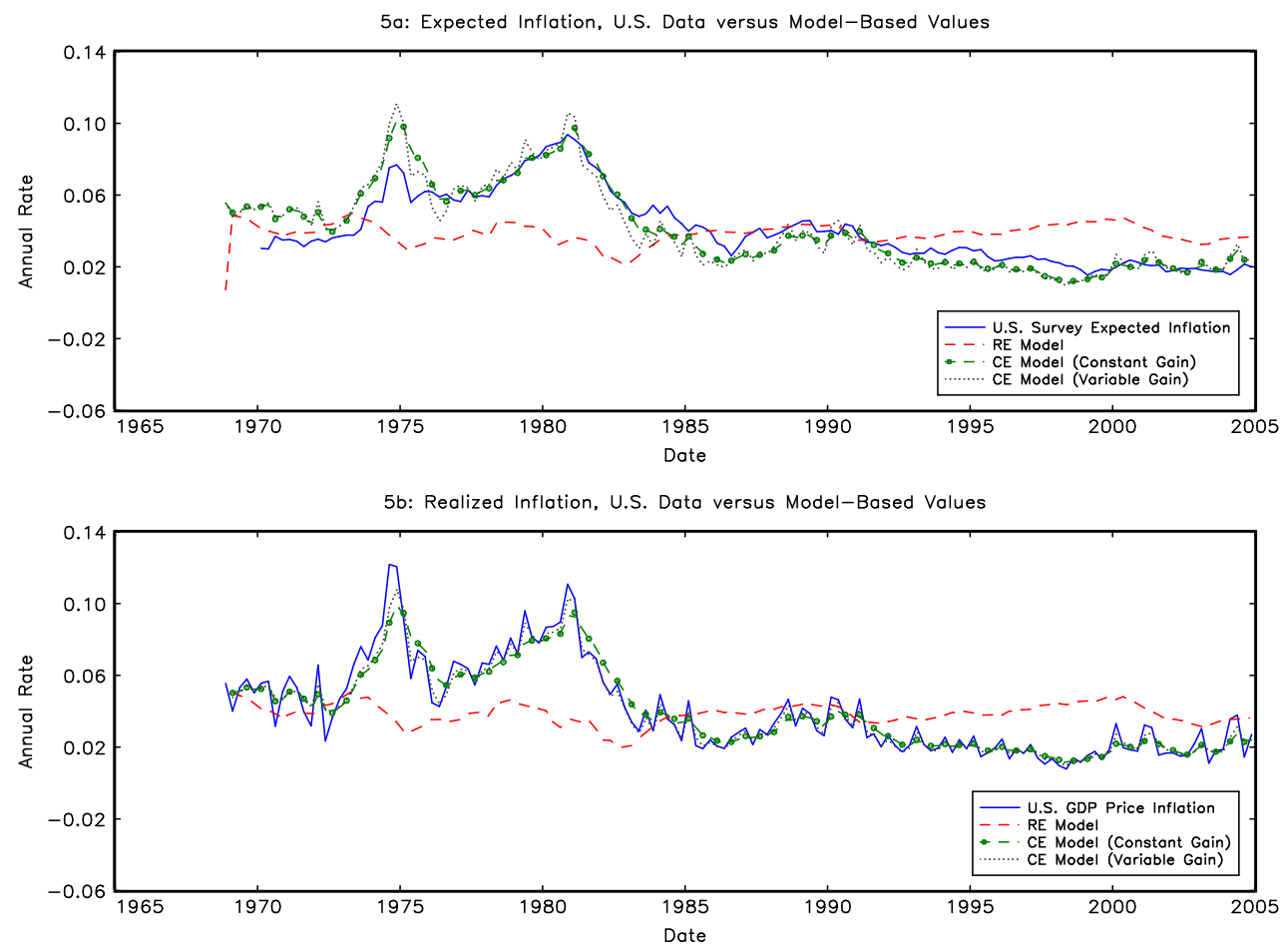

Figure 5: Comparing expected and realized U.S. inflation to model-based values.

Panel 4c plots the perceived U.S. optimal gain parameter computed directly from the perceived U.S. signal-to-noise ratio using equation (14). ${ }^{17}$ The gain parameter fluctuates from a low of 0.28 to a high of 0.87 , with the high also occurring in the early 1990s. The variation in the perceived optimal gain parameter inferred from U.S. data suggests a "variable-gain" version of the model where $\lambda^{*}$ is computed using a rolling autocorrelation coefficient for $\Delta \pi_{t}$. A rolling sample period allows the gain parameter in the agent's forecast rule (12) to adjust to perceived shifts in the underlying signal-to-noise ratio.

Figure 5 compares measures of expected and realized U.S. inflation to the corresponding model-based values. Expected inflation in U.S. data is measured by the 1-year ahead forecast for GDP price inflation from the Survey of Professional Forecasters. The sample period for the survey starts in 1970.Q1. ${ }^{18}$ For the rational expectations (RE) version of the model, expected inflation is computed from equation (11), where $\gamma=0.03, \rho=0.90, \beta=0.98$, and $y_{t}$ is the output gap from U.S. data. ${ }^{19}$ For the consistent expectations $(\mathrm{CE})$ version of the model,

\footnotetext{
${ }^{17}$ Strictly speaking, equation (14) applies only to the steady-state. Out of steady-state, McCulloch (2005) shows that the optimal gain parameter evolves according to $\lambda_{t}=\left(\lambda_{t-1}+\phi\right) /\left(1+\lambda_{t-1}+\phi\right)$. Replotting panel $4 \mathrm{c}$ using this law of motion together with the current inferred value of $\phi$ from U.S. data produced nearly identical results.

${ }^{18}$ The survey data is available from http://www.phil.frb.org/files/spf/cpie1.txt. It should be noted that model-based values of expected inflation are annualized 1-quarter rates, whereas the survey data are 1-year ahead average inflation rates.

${ }^{19}$ Recall that equation (11) implies a steady-state inflation rate of zero. For comparison with the survey, the $\mathrm{RE}$ model-based value is shifted up by a constant to match the mean of U.S. inflation over the sample period.
} 
expected inflation is computed from equation (12) with $\lambda=\lambda^{*}=0.346$. The figure also plots expected inflation for a variable-gain version of the CE model, where the gain sequence is taken from the bottom panel of Figure $4 .^{20}$ Given the model-based values for expected inflation, values for realized inflation are computed from the NKPC equation (1) where $y_{t}$ is the U.S. output gap and the markup shock $\varepsilon_{t}$ is set equal to zero each period.

Panels $5 \mathrm{a}$ and $5 \mathrm{~b}$ show that the RE model performs poorly in capturing observed movements in U.S. data, whereas both versions of the CE model perform quite well. These plots reinforce the point made earlier that Phillips-curve based inflation forecasts may frequently underperform simple univariate time series forecasts. A more detailed comparison between U.S. data and simulated data from the model is provided in section 7 .

\section{Inflation Forecast Errors}

This section characterizes the unconditional moments of inflation forecast errors. It turns out that when the actual law of motion for inflation is given by (15), the errors associated with the adaptive forecast (12) exhibit near-zero autocorrelation for most values of the gain parameter $\lambda$. Furthermore, an agent who is concerned about minimizing forecast errors can become "locked-in" to the use of the adaptive forecast. In particular, for most values of $\lambda$, the agent will perceive no accuracy gain from switching to a Phillips curve-based forecast. ${ }^{21}$

Suppose that the representative agent initially adopts the adaptive forecast given by equation (12). The initial choice could be justified for reasons of computational or informational simplicity. The forecast error observed by the agent is given by

$$
\begin{aligned}
e r r_{t+1}^{\mathrm{a} \mid \mathrm{a}} & =\pi_{t+1}-\widehat{E}_{t} \pi_{t+1}, \\
& =\frac{\gamma}{(1-\beta \lambda)} u_{t+1}+\frac{1}{(1-\beta \lambda)} \varepsilon_{t+1}-\frac{(1-\beta)}{(1-\beta \lambda)} \widehat{E}_{t} \pi_{t+1}+\frac{\gamma \rho}{(1-\beta \lambda)} y_{t},
\end{aligned}
$$

where I have made use of the actual law of motion (15). The superscript "a|a" denotes the error associated with the adaptive forecast, conditional on inflation being being generated using the adaptive forecast.

Now consider an agent who is contemplating a switch to a Phillips curve-based forecast. In deciding whether to switch forecasts, the agent keeps track of the forecast errors associated with the alternative forecast method. Before any switch occurs, the actual law of motion for $\pi_{t}$ is still given by (15). For simplicity, assume that enough time has gone by to allow the agent to have discovered the stochastic process for the driving variable, and also assume that the agent is endowed with knowledge of the slope parameter $\gamma$. With these assumptions, the Phillips curve forecast is given by the right-side of equation (11). The associated forecast error is given by

$$
\begin{aligned}
\operatorname{err}_{t+1}^{\mathrm{pc} \mid \mathrm{a}} & =\pi_{t+1}-\left[\frac{\gamma \rho}{1-\rho \beta}\right] y_{t}, \\
& =\frac{\gamma}{(1-\beta \lambda)} u_{t+1}+\frac{1}{(1-\beta \lambda)} \varepsilon_{t+1}+\frac{\beta(1-\lambda)}{(1-\beta \lambda)} \widehat{E}_{t} \pi_{t+1}-\frac{\gamma \rho \beta(\rho-\lambda)}{(1-\beta \lambda)(1-\rho \beta)} y_{t},
\end{aligned}
$$

where the superscript "pc|a" denotes the error associated with the Phillips curve forecast, conditional on inflation being generated using the adaptive forecast.

\footnotetext{
${ }^{20}$ Both versions of the CE model employ the initial condition $\widehat{E}_{t-1} \pi_{t}=\pi_{t-1}$, where $t-1$ corresponds to 1968.Q4.

${ }^{21}$ Lansing (2006) examines the concept of forecast lock-in using a standard Lucas-type asset pricing model.
} 
For comparison purposes, it is useful to compute the forecast errors that arise when inflation is governed by the rational law of motion (4). In this case, the error associated with the adaptive forecast is given by

$$
\begin{aligned}
\operatorname{err}_{t+1}^{\mathrm{a} \mid \mathrm{pc}} & =\pi_{t+1}^{\mathrm{re}}-\widehat{E}_{t} \pi_{t+1}^{\mathrm{re}}, \\
& =\frac{\gamma}{(1-\rho \beta)} u_{t+1}+\varepsilon_{t+1}-\widehat{E}_{t} \pi_{t+1}^{\mathrm{re}}+\frac{\gamma \rho}{(1-\rho \beta)} y_{t},
\end{aligned}
$$

where the superscript "a|pc" denotes the error associated with the adaptive forecast, conditional on inflation being generated using the rational Phillips curve forecast. The adaptive forecast now evolves according to recursion $\widehat{E}_{t} \pi_{t+1}^{\mathrm{re}}=\lambda \pi_{t}^{\mathrm{re}}+(1-\lambda) \widehat{E}_{t-1} \pi_{t}^{\mathrm{re}}$, where $\pi_{t}^{\mathrm{re}}$ is governed by the rational law of motion (4).

Lastly, we have the forecast errors that one normally associates with rational expectations:

$$
\begin{aligned}
\operatorname{err}_{t+1}^{\mathrm{pc} \mid \mathrm{pc}} & =\pi_{t+1}^{\mathrm{re}}-E_{t} \pi_{t+1}^{\mathrm{re}}, \\
& =\frac{\gamma}{(1-\rho \beta)} u_{t+1}+\varepsilon_{t+1},
\end{aligned}
$$

where the superscript "pc|pc" denotes the error associated with the rational Phillips curve forecast, conditional on inflation being generated using the Phillips curve forecast.

\subsection{Forecast Lock-in}

Given a sufficiently long time series of observations, the agent could compute the moments of the observed forecast errors under each of the above scenarios. Appendix A provides analytical expressions for computing the mean squared error $M S E \equiv E\left[\left(e r r_{t+1}\right)^{2}\right]$ and the autocorrelation of the forecast errors $\operatorname{Corr}\left(e r r_{t+1}, e r r_{t}\right)$. If the representative agent initially chooses the adaptive forecast, then the associated fitness measure is given by $M S E^{\mathrm{a} \mid \mathrm{a}}$. Conditional on the same law of motion, the fitness measure for the Phillips curve forecast is given by $M S E^{\mathrm{pc} \mid \mathrm{a}}$. These fitness measures are used in the following definition of forecast lock-in.

Definition 2. Lock-in of the adaptive forecast (12) occurs when: (i) the actual law of motion for $\pi_{t}$ is given by equation (15), (ii) the gain parameter is within the admissible range $0<$ $\lambda \leq 1$, and $(i i i) M S E^{\mathrm{a} \mid \mathrm{a}}=\min \left\{M S E^{\mathrm{a} \mid \mathrm{a}}, M S E^{\mathrm{pc} \mid \mathrm{a}}\right\}$.

Figure 6 plots the moments of the inflation forecast errors for $0<\lambda \leq 1$. All parameters are set to the baseline values. For ease of comparison across panels, I plot the root mean squared error RMSE. Lower values imply a more accurate forecast. Vertical lines mark the value $\lambda^{*}$ that is consistent with the perceived law of motion (13). When inflation is generated using the adaptive forecast (panels $6 \mathrm{a}$ and $6 \mathrm{c}$ ), we have $\lambda^{*}=0.346$, as demonstrated earlier in section 4. In contrast, when inflation is generated using the rational Phillips curve forecast (panels $6 \mathrm{~b}$ and $6 \mathrm{~d}$ ), we have $\lambda^{*}=0.218 .^{22}$ The lower value of $\lambda^{*}$ obtains in this case because inflation is less persistent when it evolves according to the rational law of motion (4).

Panel 6a shows that the conditions needed for lock-in of the adaptive forecast are satisfied for $0<\lambda<0.98$. In this range, the combination of inflation persistence and volatility induced by the actual law of motion (15) cause the adaptive forecast to be more accurate than the

\footnotetext{
${ }^{22}$ From Proposition 1, we have $\phi^{*}=-1 / \operatorname{Corr}\left(\Delta \pi_{t}^{\mathrm{re}}, \Delta \pi_{t-1}^{\mathrm{re}}\right)-2$. Dividing equation (10) by equation (9) yields the result that $\operatorname{Corr}\left(\Delta \pi_{t}^{\mathrm{re}}, \Delta \pi_{t-1}^{\mathrm{re}}\right)=-0.485$, such that $\phi^{*}=0.061$. Plugging this value into equation (14) yields $\lambda^{*}=0.218$.
} 

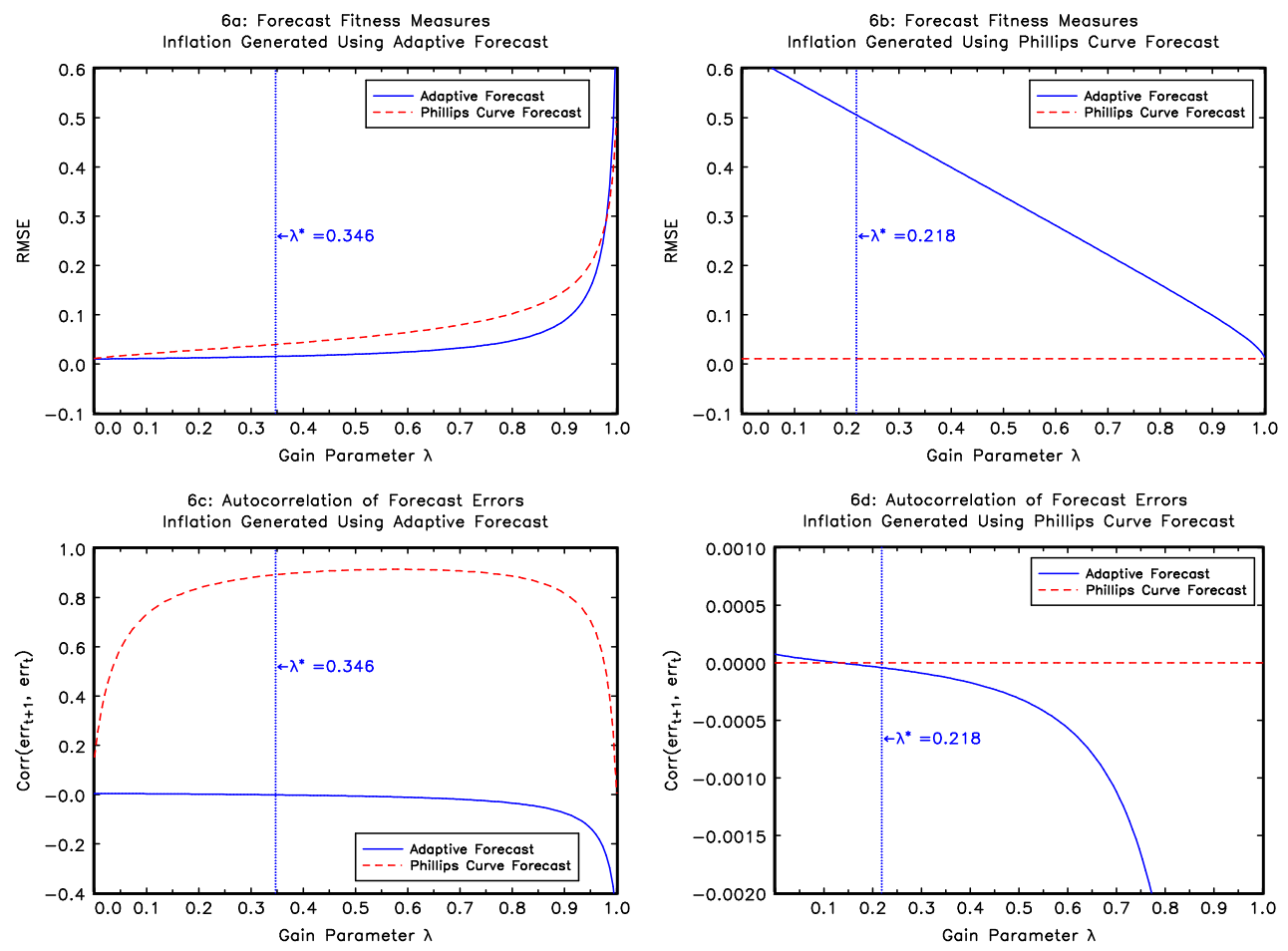

Figure 6: Root mean squared forecast error and autocorrelation of forecast errors.

Phillips curve forecast. As $\lambda \rightarrow 1$, persistence declines and volatility rises, as shown in Figure 3. Lower persistence combined with higher volatility has the effect of reducing the accuracy of the adaptive forecast relative to the Phillips curve forecast. For $0.98 \leq \lambda<1$, the conditions needed for lock-in are no longer satisfied.

Notice that the plot of $R M S E$ for the adaptive forecast is relatively flat in the vicinity of $\lambda^{*}$. This validates the conjecture put forth earlier in the discussion of Figure 2; forecast accuracy does not suffer much as long as $\lambda$ remains in the general vicinity of $\lambda^{*}$. The intuition for why lock-in occurs is straightforward. In computing the forecast fitness measures, the representative agent views the evolution of $\pi_{t}$ as being determined outside of his control. In equilibrium, of course, the chosen forecast method does in fact influence the evolution of $\pi_{t}$. When the agent initially chooses the adaptive forecast, the resulting law of motion for $\pi_{t}$ is such that the Phillips curve forecast is no longer the most accurate. Similar to the lockin phenomena described by David (1985) and Arthur (1989), externalities that arise from an initial choice can lead to irreversibilities that may cause agents to stick with an inferior technology. Here, the adaptive forecast can be viewed as an inferior prediction technology because the mean squared forecast error could be lowered if the representative agent could be induced to switch to the Phillips curve forecast.

Panel 6b shows the unsurprising result that the rational Phillips curve forecast is always more accurate than the adaptive forecast when inflation is actually generated using the Phillips curve forecast. Comparing across panels, the rational Phillips curve forecast in panel $6 \mathrm{~b}$ yields $R M S E=0.0103$, whereas the adaptive forecast in panel 6a yields $R M S E=0.0152$ when 
$\lambda=\lambda^{*}$. Thus, the typical forecast error observed under consistent expectations is only about 50 basis points higher than that observed under rational expectations. This difference would be even smaller if we took into account real-time measurement errors in $y_{t}$, or empirical instability in the parameters $\gamma$ and $\rho$, the latter being a policy-dependent parameter that is subject to the Lucas critique. Table 2 provides a quantitative comparison of the forecast fitness measures under each of the forecast scenarios.

Table 2: Forecast Fitness Measures (RMSE)

\begin{tabular}{lcc}
\hline \hline & \multicolumn{3}{c}{$\pi_{t}$ forecasted by: } \\
$\pi_{t}$ generated by: & Adaptive Forecast $\left(\lambda=\lambda^{*}\right)$ & Phillips Curve Forecast \\
Adaptive Forecast $\left(\lambda=\lambda^{*}\right)$ & 0.015 & 0.040 \\
Phillips Curve Forecast & 0.506 & 0.010 \\
\hline
\end{tabular}

Parameter values: $\beta=0.98, \gamma=0.03, \rho=0.90, \sigma_{\varepsilon}=\sigma_{u}=0.01$

Panel $6 \mathrm{c}$ shows that for most values of $\lambda$, the autocorrelation of adaptive forecast errors is close to zero, making it difficult for the agent to detect a misspecification of the forecast rule. The autocorrelation starts out narrowly positive for $\lambda$ near zero, remains nearly constant for most of the admissible range, and then turns down sharply as $\lambda \rightarrow 1$. When $\lambda=\lambda^{*}$, we have $\operatorname{Corr}\left(\operatorname{err}_{t+1}^{\mathrm{a} \mid \mathrm{a}}, \operatorname{err}_{t}^{\mathrm{a} \mid \mathrm{a}}\right)=-0.0014$. At the same value of $\lambda$, the Phillips curve forecast is characterized by highly persistent forecast errors, with $\operatorname{Corr}\left(\operatorname{err}_{t+1}^{\mathrm{pc} \mid \mathrm{a}}, \operatorname{err}_{t}^{\mathrm{pc} \mid \mathrm{a}}\right)=0.892$.

In panel 6d, the autocorrelation of forecast errors is identically zero for the rational Phillips curve forecast. The errors observed for the adaptive forecast once again exhibit near-zero autocorrelation for most values of $\lambda$. This result is an inherent feature of the error-correction approach to forecasting, as embodied in the forecast rule (12).

\section{$7 \quad$ Model Simulations}

Figure 7 plots simulated data for three different forms of inflation expectations. The left-side panels show the results for rational expectations (RE). The middle panels show the results for consistent expectations (CE), where the gain parameter is held constant at the theoretical equilibrium value $\lambda^{*}=0.346$ implied by Definition 1 . The right-side panels show the results for an alternative "variable-gain" version of the CE model. Under this setup, the gain parameter evolves according to the out-of-steady-state version of equation (14) given by

$$
\lambda_{t}=\frac{\lambda_{t-1}+\phi}{1+\lambda_{t-1}+\phi}
$$

where $\phi$ is inferred from the autocorrelation of $\Delta \pi_{t}$ over a 20-year (80-quarter) rolling sample period. ${ }^{23}$ Recall that the autocorrelation of $\Delta \pi_{t}$ uniquely identifies the perceived signal-tonoise ratio $\phi$, as shown by Proposition 1 . The use of a 20-year rolling sample period allows for slowly-evolving perceptions of $\phi$, where perceptions are based on each generation's inflation experience. Alternatively, we may think of the representative agent as an econometrician who views 20-year-old inflation data as being uninformative about the current value of $\phi$. Along

\footnotetext{
${ }^{23}$ Use of the steady-state relationship (14) in place of equation (30) yields very similar results. For the initial 20 years of the simulation, I impose $\lambda_{t}=\lambda^{*}=0.346$. Summary statistics are then computed after dropping the first 200 quarters of simulated data.
} 

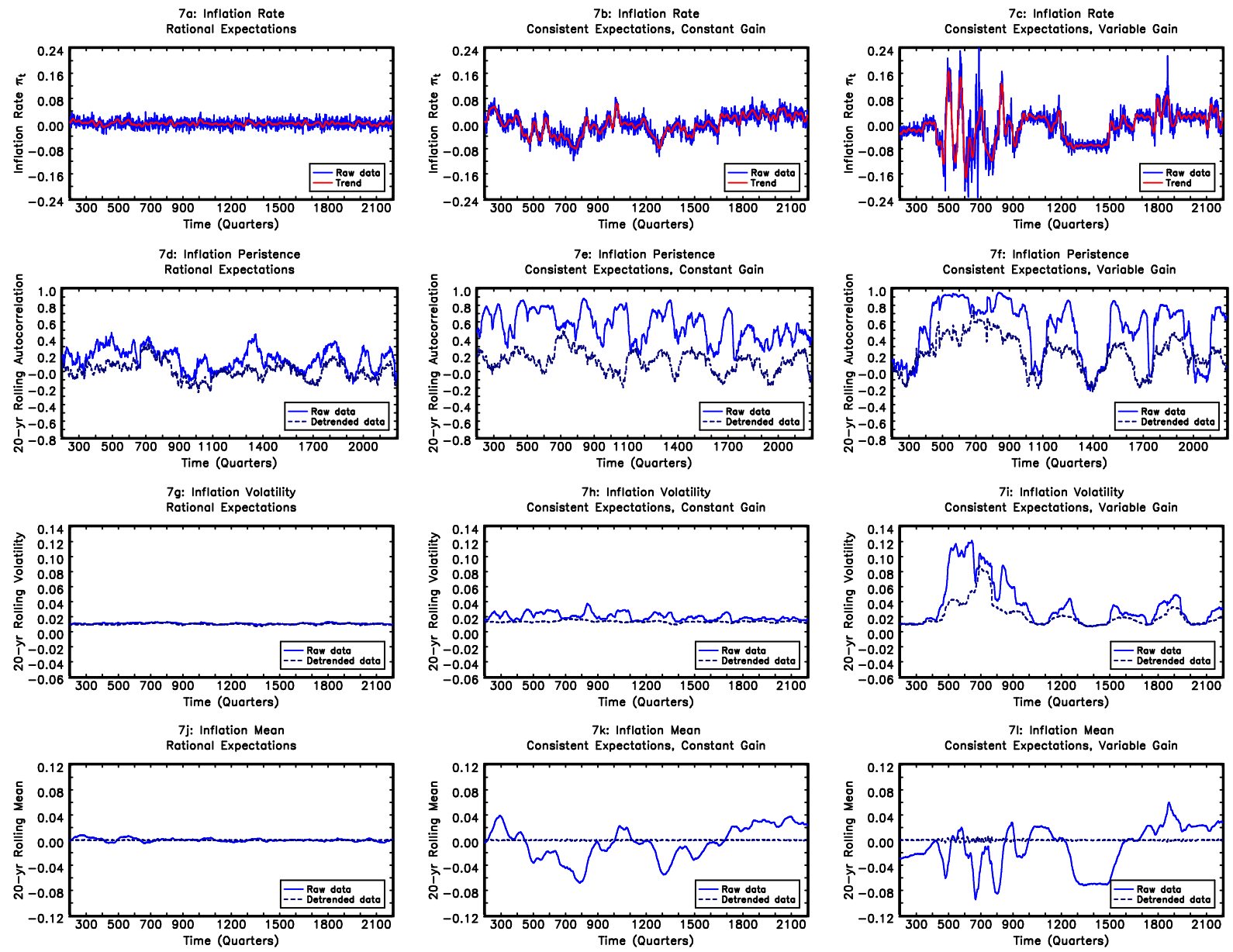

Figure 7: Simulated inflation dynamics for three different forms of expectations.

these lines, Stock and Watson (1996) find strong evidence of structural instability in various U.S. inflation series. They also find that 10 - and 20-year rolling regression models tend to perform better than fixed coefficient models in out-of-sample forecasts. Friedman (1979, p. 33) points out that much of the empirical time series analysis in economics is based on "some rough form of rolling sample period." The basic nature of the simulation results is robust to changes to the length of the rolling sample period. The fact that $f(\lambda)$ lies very close to the 45degree line in Figure 2 implies that a small amount of sampling variation in the autocorrelation of $\Delta \pi_{t}$ can translate into large shifts in the perceived optimal gain parameter.

In the variable-gain $\mathrm{CE}$ model, the actual law of motion for inflation is nonlinear and thus capable of generating time-varying persistence and volatility. ${ }^{24}$ At times during variablegain simulation, the rolling autocorrelation of $\Delta \pi_{t}$ may yield the result that $\phi<0$, which is infeasible for a ratio of two variances. When this occurs, $\phi$ is set equal to a very small positive number, i.e., $1 \times 10^{-10}$. The discussion below focuses mainly on measures of persistence and

\footnotetext{
${ }^{24}$ Laxton, Rose, and Tambakis (1999) review the empirical evidence for nonlinearities in the U.S. Phillips curve relationship that may exist for structural reasons separate from the expectations channel explored here.
} 
volatility computed from the detrended inflation data, since these are not unduly influenced by low-frequency swings in the level of inflation.

Comparing across panels $7 \mathrm{a}, 7 \mathrm{~b}$, and $7 \mathrm{c}$, we see that the same sequence of random shocks can lead to vastly different inflation dynamics, depending on the form of inflation expectations. The RE model's detrended inflation data exhibits very mild variation in persistence (panel $7 \mathrm{~d}$ ) and essentially no variation in volatility (panel $7 \mathrm{j}$ ). Detrended data from the constantgain CE model exhibits a fair amount of variation in persistence (panel 7e), but very little variation in volatility (panel $7 \mathrm{~h}$ ). Detrended data from the variable-gain CE model exhibits large variations in both persistence (panel 7f) and volatility (panel 7i).

In stark contrast to the RE model, both versions of the $\mathrm{CE}$ model produce low-frequency swings in the level of inflation, as measured by either the band pass filter trends (panels $7 \mathrm{~b}$ and $7 \mathrm{c}$ ) or the 20-year rolling sample means (panels $7 \mathrm{k}$ and 71 ). The low-frequency swings are not caused by changes in monetary policy. Instead, these movements derive solely from the near-random walk behavior of $\pi_{t}$ under consistent expectations. The CE-version of the NKPC can be written as

$$
\pi_{t}=\frac{\beta \lambda^{*}}{1-\beta \lambda^{*}}\left[(1-\lambda) \pi_{t-1}+(1-\lambda)^{2} \pi_{t-2}+\ldots\right]+\left[\frac{\gamma}{1-\beta \lambda^{*}}\right] y_{t}+\left[\frac{1}{1-\beta \lambda^{*}}\right] \varepsilon_{t},
$$

which implies that the sum of the weights on lagged inflation is $\beta\left(1-\lambda^{*}\right) /\left(1-\beta \lambda^{*}\right)=$ 0.970 when $\beta=0.98$ and $\lambda^{*}=0.346$. Given the highly persistent nature of $\pi_{t}$ observed in equilibrium, it would be very difficult for the agent to the reject the null hypothesis of a unit root in inflation, thus lending support for the perceived law of motion (13).

An enormous literature has explored explanations for the "Great Inflation" of the 1970s and the subsequent "Volcker disinflation" of the early 1980s. Theories about the rise and fall of U.S. inflation fall roughly into one of three categories: bad luck theories (which emphasize chance events outside the Fed's control), policy mistake theories (which emphasize discretionary actions by Fed policymakers), and combination theories (where chance and discretion both play a role). The ultimate bad-luck theory is that U.S. inflation is governed by a random-walk process or something close to one. This means that a sequence of white-noise shocks can generate large excursions in the inflation rate without any fundamental change in the underlying economy. Agents living in such an economy observe one history. They may wish to know why a specific pattern emerges in the data but there is no explanation to be found. According to this theory, there is nothing special about the 1970s and 1980s and similar events can happen again, given enough time. King and Watson (1994) present evidence that post-war U.S. inflation is indeed governed by a random-walk process.

The variable-gain CE model produces some episodes where the 20-year rolling measures of persistence, volatility, and the level of inflation all trace out hump-shaped patterns. These patterns are similar to those in post-World II U.S. data. The simulation results suggest that white-noise fundamental shocks, propagated via the expectations feedback mechanism, could have played an important role in producing the historical pattern of U.S. inflation. Indeed, Blinder (1982) argues that oil and food price shocks, coupled with pent-up inflation from the release of the Nixon wage-price controls in 1974, can account for most of the rise in inflation during the 1970s. He also argues that the absence of these same factors can account for most of the fall in inflation during the early 1980s. More recently, Sims and Zha (2006) argue that the primary source of the rise and fall of U.S. inflation was a "changing array of major disturbances" that occurred during a relatively stable monetary policy regime. 


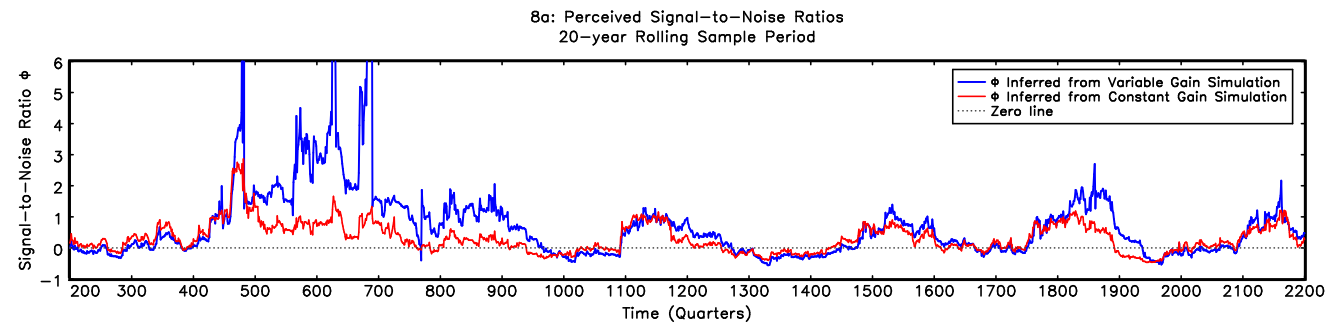

8b: Variable Gain versus Constant Gain

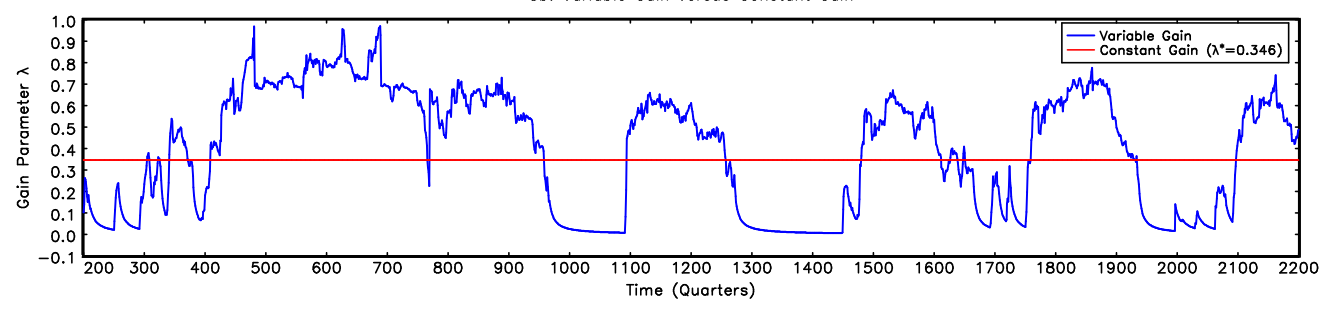

8c: Forecast Fitness Comparison

Inflation Generated Using Variable Gain Forecast

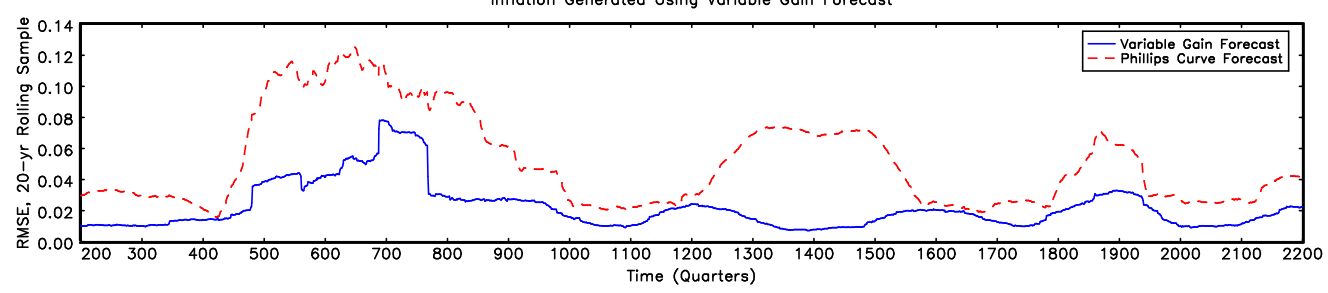

Figure 8: Additional plots for the variable-gain simulation.

At the peak of the Great Inflation in 1979, Fed Chairman Volcker acknowledged the importance of inflation expectations as a driving force for realized inflation. He said: "Inflation feeds in part on itself, so part of the job of returning to a more stable and more productive economy must be to break the grip of inflationary expectations." ${ }^{25}$ Theories about the Volcker disinflation typically emphasize the role of the Fed credibility, noting that the rate at which credibility accumulates depends on the nature of inflation expectations. ${ }^{26}$ This idea connects back to the CE model interpretation of the perceived signal-to-noise ratio as an inverse measure of central bank credibility. In the next section of the paper, I discuss some possibilities for extending the present analysis to incorporate explicit changes in monetary policy.

Figure 8 provides additional justification for the variable-gain setup. Panel 8 a plots the signal-to-noise ratios inferred from the rolling autocorrelation of $\Delta \pi_{t}$ for both the constantgain and variable-gain simulations. The inferred value of $\phi$ from the constant-gain simulation exhibits a fair amount of variation. From the agent's perspective, the presence of this stochastic volatility would appear to justify a switch to a variable-gain forecasting algorithm. Once the switch occurs, the volatility of the inferred value of $\phi$ would become magnified.

Panel $8 \mathrm{~b}$ plots the time-path of the variable gain parameter. The average value of the gain parameter over the simulation is 0.393 , with a standard deviation of 0.275 . The gain rises sharply in response to upward spikes in the inferred signal-to-noise ratio. These episodes

\footnotetext{
${ }^{25}$ See Volcker (1979), pp. 888-889.

${ }^{26}$ For references to the literature, see Huh and Lansing (2000) and Erceg and Levin (2003).
} 
might interpreted as a recurring "credibility crises" or "inflation scares" which cause the representative agent to heavily discount the central bank's past track record on inflation. ${ }^{27}$ Deflation scares are also possible. Lastly, panel $7 \mathrm{c}$ shows that when inflation is actually generated using the variable-gain forecast, the agent perceives no accuracy gain from switching to the Phillips curve forecast. For this experiment, the RMSE for each forecast is computed over a 20-year rolling sample period.

Table 3 provides a quantitative comparison of the forecast errors across the three forms of inflation expectations. The RE model delivers the most-accurate forecasts (as indicated by the lowest $R M S E$ value), whereas the variable-gain $\mathrm{CE}$ model delivers the least-accurate forecasts. However, as shown earlier in section 6 and in the bottom panel of figure 8 , if the representative agent initially chooses an adaptive forecast rule, then the agent is unlikely to perceive any accuracy gain from switching to the (rational) Phillips curve forecast. Under either version of the $\mathrm{CE}$ model, the forecast errors are close to white noise. If we assume that the distribution of the model autocorrelation statistic is approximately Gaussian, then the conventional standard error formula for the variable-gain CE model implies $-0.10 /(1 / \sqrt{T}) \approx-2.0$. Solving this formula yields the result that a sample size of at least $T \approx 400$ quarters, or 100 years, would be needed to reject the hypothesis of no autocorrelation in the forecast error. In practice, a even larger sample size would be needed to account for the sampling error of the model autocorrelation statistic.

Table 3: Comparison of Inflation Forecast Errors

\begin{tabular}{|c|c|c|c|}
\hline \multirow[b]{2}{*}{ Statistic } & \multicolumn{3}{|c|}{ Model Simulations } \\
\hline & $\mathrm{RE}$ & $\begin{array}{c}\text { CE } \\
\text { Constant } \\
\text { Gain }\end{array}$ & $\begin{array}{c}\mathrm{CE} \\
\text { Variable } \\
\text { Gain }\end{array}$ \\
\hline$R M S E$ & 0.010 & 0.015 & 0.027 \\
\hline $\operatorname{Corr}\left(\operatorname{err}_{t}, \operatorname{err}_{t-1}\right)$ & 0.00 & 0.01 & -0.10 \\
\hline $\operatorname{Corr}\left(\operatorname{err}_{t}, \operatorname{err}_{t-2}\right)$ & -0.01 & -0.01 & -0.01 \\
\hline $\operatorname{Corr}\left(\operatorname{err}_{t}, \operatorname{err}_{t-3}\right)$ & 0.00 & 0.00 & 0.00 \\
\hline
\end{tabular}

Notes: Statistics above refer to raw data from a 2000-quarter simulation after dropping 200 quarters. The variable-gain CE model uses a 20-year (80-quarter) rolling sample period for computing the perceived signal-to-noise ratio $\phi$. Parameter values: $\beta=0.98, \gamma=0.03, \rho=0.90, \sigma_{\varepsilon}=\sigma_{u}=0.01$.

Table 4 compares the moments of U.S. data with the corresponding moments computed from model simulations. Statistics are presented for both raw and detrended data. I focus on the behavior of detrended inflation since this controls for the presence of low-frequency swings in the raw data. The standard deviation of detrended inflation from the variable-gain $\mathrm{CE}$ model is 0.027 - the largest among the three models. The corresponding figure for long-run U.S. CPI inflation is 0.073, whereas the figure for U.S. GDP price inflation in the post-World War II sample period is 0.016. Detrended inflation data from the variable-gain CE model exhibits positive skewness and excess kurtosis. These features are also present in detrended

\footnotetext{
${ }^{27}$ Goodfriend (1993) defines an inflation scare as a significant increase in the long-term nominal interest rate that is driven solely by an upward jump in private-sector expectations about future inflation-absent any central bank action to push up short-term interest rates.
} 
U.S. inflation data. The persistence of detrended inflation is highest with the variable-gain CE model, providing the best match with U.S. data. Appendix B reports the amplitude of the variation in the 20 -year rolling summary statistics. Again, the variable-gain CE model seems to provide the best match with the U.S. data, confirming the informal visual comparison between Figure 1 and Figure 7.

Table 4: Unconditional Moments, Raw and Detrended Data

\begin{tabular}{|c|c|c|c|c|c|}
\hline \multirow[b]{4}{*}{ Statistic } & \multicolumn{2}{|c|}{ U.S. Data } & \multicolumn{3}{|c|}{ Model Simulations } \\
\hline & CPI & GDP-PI & & $\mathrm{CE}$ & $\mathrm{CE}$ \\
\hline & 1871.Q1 to & 1949.Q1 to & & Constant & Variable \\
\hline & 2004.Q4 & 2004.Q4 & $\mathrm{RE}$ & Gain & Gain \\
\hline \multirow{2}{*}{ Std. Dev. $\left(\pi_{t}\right)$} & 0.084 & 0.026 & 0.011 & 0.034 & 0.058 \\
\hline & 0.073 & 0.016 & 0.010 & 0.013 & 0.027 \\
\hline \multirow{2}{*}{ Skew. $\left(\pi_{t}\right)$} & 0.09 & 1.09 & 0.08 & -0.27 & 0.13 \\
\hline & 0.76 & 2.45 & 0.02 & 0.11 & 0.90 \\
\hline \multirow{2}{*}{$\operatorname{Kurt.}\left(\pi_{t}\right)$} & 5.93 & 4.66 & 3.10 & 2.66 & 5.21 \\
\hline & 8.58 & 18.2 & 3.12 & 3.07 & 28.3 \\
\hline \multirow{2}{*}{$\operatorname{Corr}\left(\pi_{t}, \pi_{t-1}\right)$} & 0.47 & 0.81 & 0.20 & 0.86 & 0.88 \\
\hline & 0.29 & 0.49 & 0.02 & 0.14 & 0.46 \\
\hline \multirow{2}{*}{$\operatorname{Corr}\left(\pi_{t}, \pi_{t-2}\right)$} & 0.22 & 0.74 & 0.17 & 0.85 & 0.84 \\
\hline & -0.02 & 0.32 & -0.02 & 0.07 & 0.30 \\
\hline \multirow{2}{*}{$\operatorname{Corr}\left(\pi_{t}, \pi_{t-3}\right)$} & 0.24 & 0.69 & 0.15 & 0.84 & 0.80 \\
\hline & 0.01 & 0.19 & -0.04 & 0.02 & 0.15 \\
\hline $\operatorname{Corr}\left(\Delta \pi_{t}, y_{t}\right)$ & - & 0.09 & 0.05 & 0.03 & 0.03 \\
\hline $\operatorname{Corr}\left(\Delta \pi_{t}, y_{t-1}\right)$ & - & 0.03 & -0.04 & 0.01 & 0.02 \\
\hline $\operatorname{Corr}\left(\Delta \pi_{t}, \Delta \pi_{t-1}\right)$ & -0.27 & -0.34 & -0.48 & -0.45 & -0.33 \\
\hline
\end{tabular}

Notes: Statistics for $\pi_{t}$ are based on raw data (top number) and detrended data (bottom number). The detrended data are obtained using the band pass filter of Christiano and Fitzgerald (2003). Statistics for $\Delta \pi_{t}$ and $y_{t}$ are based on raw data. Model statistics are computed from a 2000 quarter simulation after dropping 200 quarters. The variable gain CE model uses a 20-year (80-quarter) rolling sample period for computing the perceived signal-to-noise ratio $\phi$. Parameter values: $\beta=.98$, $\gamma=0.03, \rho=0.90, \sigma_{\varepsilon}=\sigma_{u}=0.01$.

\section{Extensions of the Model}

\subsection{Higher-Order Consistency of the Variable-Gain Setup}

In the variable-gain $\mathrm{CE}$ model, the agent perceives the signal-to-noise ratio $\phi$ to be timevarying. This perception turns out to be justified by the variation in $\phi$ that is inferred from a 20-year rolling autocorrelation of $\Delta \pi_{t}$. A more sophisticated agent might adopt a perceived law of motion for the signal-to-noise ratio and then apply the Kalman filter to extract an optimal estimate each period. One possibility for the perceived law of motion is

$$
\begin{aligned}
\log \left(\phi_{t}\right) & =\log \left(\bar{\phi}_{t}\right)+\xi_{t}, & & \xi_{t} \sim N\left(0, \sigma_{\xi}^{2}\right), \\
\log \left(\bar{\phi}_{t}\right) & =\log \left(\bar{\phi}_{t-1}\right)+\omega_{t}, & & \omega_{t} \sim N\left(0, \sigma_{\omega}^{2}\right),
\end{aligned}
$$


where $\operatorname{Cov}\left(\xi_{t}, \omega_{t}\right)=0$, and the geometric random walk specification ensures $\phi_{t}>0 .{ }^{28}$ In this case, the optimal estimate of $\log \left(\phi_{t}\right)$ is determined by an exponentially-weighted moving average of past estimates, where the perceived optimal gain parameter that governs the weighting scheme depends on the higher-order signal-to-noise ratio $\sigma_{\omega}^{2} / \sigma_{\xi}^{2}$. Following the methodology outlined in Proposition 1, the agent could identify the value of the higher-order signal-to-noise ratio from the autocorrelation of $\Delta \log \left(\phi_{t}\right)$ and proceed accordingly.

The above discussion shows that imposing higher-order consistency on the variable-gain CE model is no doubt feasible. Such an arrangement brings with it the assumption of greater computational sophistication on the part of the representative agent. Such assumptions, when extrapolated to their ultimate conclusion, lead back towards the rational expectations equilibrium. Another possible approach would be to adopt one of the many variable-gain forecasting algorithms that have been developed in the vast literature on exponential smoothing. These algorithms adjust the gain parameter up or down over time in a controlled manner to account for changes in the underlying covariance structure of the forecast variable. ${ }^{29}$ The approach taken in this paper is to assume that the agent adjusts for perceived shifts in the signal-to-noise ratio by discarding old data - much like an econometrician would do.

\subsection{Shifts in Policy-Dependent Parameters}

The present analysis holds all policy-dependent parameters constant. An extension of the model could allow for shifts in the coefficients of the central bank's policy rule that would influence the reduced-form stochastic properties of the driving variable $y_{t}$ via equation (2). A simple example is provided in footnote 9 . A more comprehensive treatment of monetary policy would embed the consistent expectations equilibrium concept into a fully-articulated New Keynesian model that includes a micro-founded IS equation. The introduction of consistent expectations in place of rational expectations in such a model is motivated by the ability of the former to match important features of U.S. inflation dynamics. Under consistent expectations, the persistence of inflation is governed by the equilibrium value of the gain parameter which, in turn, is linked to the autocorrelation of inflation changes $\operatorname{Corr}\left(\Delta \pi_{t}, \Delta \pi_{t-1}\right)$. Since this autocorrelation is influenced by monetary policy, the central bank's optimal policy rule would need to take into account the manner in which private-sector expectations are formed. ${ }^{30}$

The model could also be extended to allow for actual shifts in the central bank's inflation target. As mentioned in the introduction, such an extension would require the use of a modified (and more complicated) NKPC that is log-linearized around a non-zero trend inflation rate. Recall that the representative agent's perceived law of motion (13) already allows for evolving shifts in the central bank's inflation target. Introducing actual shifts in the inflation target according to some law of motion would bring the agent's perception closer to reality.

\footnotetext{
${ }^{28}$ In estimating an unobserved components model on U.S. inflation data, Stock and Watson (2005) assume that the variances of the permanent and transitory shocks follow independent geometric random walks. In contrast, equations (32) and (33) assume that the ratio of these two variances follows a geometric random walk with noise.

${ }^{29}$ For a review of variable-gain smoothing algorithms, see Gardner (1985, p. 19).

${ }^{30}$ Recent research on expectations and optimal monetary policy includes: Rudebusch (2002), Amato and Laubach (2003), Steinsson (2003), Lansing and Trehan (2003), Orphanides and Williams (2005), Ball, Mankiw, and Reis (2005), Levin and Moessner (2005), Woodford (2005), and Gaspar, Smets, and Vestin (2006), among others.
} 


\section{Concluding Remarks}

Evolving theories about inflation expectations, led by the contributions of Phelps (1967), Friedman (1968), Sargent (1971), and Lucas (1972, 1973) have played a important role in developing the modern view of the Phillips curve. The current workhorse version for macroeconomics is the forward-looking New Keynesian Phillips curve with rational expectations. The advantages of the NKPC are its tractability and its link to microfoundations that assume optimizing behavior on the part of agents and firms. The biggest disadvantage of the NKPC is its inability to account for important features of U.S. inflation dynamics.

This paper showed that a plausible and justifiable departure from 100-percent rationalityin the form of consistent expectations - allows the NKPC to reproduce many of the features observed in long-run U.S. inflation data, including: time-varying persistence and volatility, positive skewness, excess kurtosis, and pronounced low-frequency swings. Under consistent expectations, the agent's forecast rule is optimized for a set of beliefs and observations about inflation. The forecast errors observed by the agent are close to white noise, making it difficult to detect a misspecification of the forecast rule. Moreover, from the individual agent's perspective, switching to a (rational) NKPC-based forecast would appear to reduce forecast accuracy, so there is no incentive to switch.

In the variable-gain version of consistent expectations, endogenous shifts in the agent's perceived signal-to-noise ratio (which might be viewed as an inverse-measure of central bank credibility) give rise to changes in inflation persistence and volatility. These changes take place in the absence of any underlying shifts in monetary policy. This feature of the model offers a possible explanation for the end-of-sample decline in U.S. inflation persistence shown in Figure 1, which has occurred during a period of seemingly-unchanged monetary policy.

Rational expectations are sometimes called "model consistent expectations." A more precise term would be "actual-model consistent expectations," because the maintained assumption is that the agent knows the actual model. In contrast, the equilibrium concept employed in this paper could be described as "perceived-model consistent expectations," because the agent's forecast rule is optimal, conditional on a perceived law of motion for inflation and observed moments of the inflation time series.

In the modified NKPC developed here, expected inflation is an exponentially-weighted moving average of past observed inflation rates. The consistent expectations equilibrium concept uniquely pins down the value of the gain parameter that governs the weights assigned to past rates of inflation. This result harkens back to the "accelerationist controversy" identified by Sargent (1971, p. 35) who argued persuasively that any weighting scheme involving past rates of inflation should "be compatible with the observed evolution of the rate of inflation." Sargent's criterion is precisely the logic that underlies the choice of the gain parameter in the consistent expectations equilibrium. 


\section{A Appendix: Moments of Inflation Forecast Errors}

This appendix provides analytical expressions for the moments used in plotting Figure 6.

\section{A.1 Inflation Generated Using Adaptive Forecast}

First consider the case when the representative agent employs the adaptive forecast (12). In equilibrium, the actual of motion is given by equation (15). Both the adaptive forecast and the Phillips curve forecast are unbiased, i.e., $E\left(e r r_{t+1}^{\mathrm{a} \mid \mathrm{a}}\right)=E\left(e r r_{t+1}^{\mathrm{pc} \mid \mathrm{a}}\right)=0$, where $E(\cdot)$ denotes the unconditional mean.

Starting from (26), the fitness measure for the adaptive forecast is given by

$$
\begin{aligned}
M S E^{\mathrm{a} \mid \mathrm{a}}= & \frac{\gamma^{2}}{(1-\beta \lambda)^{2}\left(1-\rho^{2}\right)} \sigma_{u}^{2}+\frac{1}{(1-\beta \lambda)^{2}} \sigma_{\varepsilon}^{2}+\frac{(1-\beta)^{2}}{(1-\beta \lambda)^{2}} \operatorname{Var}\left(\widehat{E}_{t} \pi_{t+1}\right) \\
& -\frac{2(1-\beta) \gamma \rho}{(1-\beta \lambda)^{2}} \operatorname{Cov}\left(\widehat{E}_{t} \pi_{t+1}, y_{t}\right),
\end{aligned}
$$

where $\operatorname{Var}\left(\widehat{E}_{t} \pi_{t+1}\right)$ and $\operatorname{Cov}\left(\widehat{E}_{t} \pi_{t+1}, y_{t}\right)$ are given by (17) and (25). Since $\operatorname{Cov}\left(\widehat{E}_{t} \pi_{t+1}, y_{t}\right)>$ 0 , the adaptive forecast tracks movements in the driving variable, similar to the case of rational expectations (11). Movements in the driving variable are persistent, so the tracking feature improves the accuracy of the forecast.

It can be shown that the covariance of sequential forecast errors is given by

$$
\begin{aligned}
\operatorname{Cov}\left(\operatorname{err}_{t+1}^{\mathrm{a} \mid \mathrm{a}}, \operatorname{err}_{t}^{\mathrm{a} \mid \mathrm{a}}\right)= & \frac{\gamma^{2}[\rho-\lambda+\beta \lambda(1-\rho)]}{(1-\beta \lambda)^{3}\left(1-\rho^{2}\right)} \sigma_{u}^{2}-\frac{(1-\beta) \lambda}{(1-\beta \lambda)^{3}} \sigma_{\varepsilon}^{2}+\frac{(1-\beta)^{2}(1-\lambda)}{(1-\beta \lambda)^{3}} \operatorname{Var}\left(\widehat{E}_{t} \pi_{t+1}\right) \\
& -\frac{(1-\beta) \gamma \rho[1+\rho+\beta \lambda(1-\rho)-2 \lambda]}{(1-\beta \lambda)^{3}} \operatorname{Cov}\left(\widehat{E}_{t} \pi_{t+1}, y_{t}\right) .
\end{aligned}
$$

Dividing the above equation by $M S E^{\mathrm{a} \mid \mathrm{a}}=\operatorname{Var}\left(\operatorname{err}_{t+1}^{\mathrm{a} \mid \mathrm{a}}\right)$ from (A.1) yields a complicated expression for $\operatorname{Corr}\left(\operatorname{err}_{t+1}^{\mathrm{a} \mid \mathrm{a}}, \operatorname{err}_{t}^{\mathrm{a} \mid \mathrm{a}}\right)$. However, the following simplified version can be obtained by letting $\beta \rightarrow 1$

$$
\operatorname{Corr}\left(\operatorname{err}_{t+1}^{\mathrm{a} \mid \mathrm{a}}, \operatorname{err}_{t}^{\mathrm{a} \mid \mathrm{a}}\right)_{\beta \rightarrow 1}=\frac{\gamma^{2} \rho}{\gamma^{2}+\left(1-\rho^{2}\right)\left(\sigma_{\varepsilon}^{2} / \sigma_{u}^{2}\right)},
$$

which bears a striking resemblance to the autocorrelation of inflation under rational expectations, as given by (6) A comparison of (6) and (A.3) reveals that parameter configurations which give rise to low autocorrelation of inflation under rational expectations will imply an even lower autocorrelation of forecast errors under adaptive expectations.

Next, we start from (27). The fitness measure for the Phillips curve forecast is given by

$$
\begin{aligned}
M S E^{\mathrm{pc} \mid \mathrm{a}}= & \frac{\gamma^{2}}{(1-\beta \lambda)^{2}}\left[1+\frac{\rho^{2} \beta^{2}(\rho-\lambda)^{2}}{(1-\rho \beta)^{2}\left(1-\rho^{2}\right)}\right] \sigma_{u}^{2}+\frac{1}{(1-\beta \lambda)^{2}} \sigma_{\varepsilon}^{2}+\frac{\beta^{2}(1-\lambda)^{2}}{(1-\beta \lambda)^{2}} \operatorname{Var}\left(\widehat{E}_{t} \pi_{t+1}\right) \\
& -\frac{2 \gamma \rho \beta^{2}(\rho-\lambda)(1-\lambda)}{(1-\beta \lambda)^{2}(1-\rho \beta)} \operatorname{Cov}\left(\widehat{E}_{t} \pi_{t+1}, y_{t}\right),
\end{aligned}
$$

where $\operatorname{Var}\left(\widehat{E}_{t} \pi_{t+1}\right)$ and $\operatorname{Cov}\left(\widehat{E}_{t} \pi_{t+1}, y_{t}\right)$ continue to be given by (17) and (25).

Proceeding as before, the covariance of sequential forecast errors is given by

$$
\begin{aligned}
\operatorname{Cov}\left(\operatorname{err}_{t+1}^{\mathrm{pc} \mid \mathrm{a}}, \operatorname{err}_{t}^{\mathrm{pc} \mid \mathrm{a}}\right)= & \frac{\gamma^{2} \beta}{(1-\beta \lambda)^{3}}\left[1-\frac{\rho^{2} \beta(\rho-\lambda)}{(1-\rho \beta)\left(1-\rho^{2}\right)}\right]\left[\lambda(1-\lambda)-\frac{\rho(\rho-\lambda)(1-\beta \lambda)}{(1-\rho \beta)}\right] \sigma_{u}^{2} \\
& +\frac{\gamma \rho \beta^{2}(1-\lambda)}{(1-\beta \lambda)^{3}}\left[\lambda(1-\lambda)-\frac{(\rho-\lambda)[\rho(1-\beta \lambda)+1-\lambda]}{(1-\rho \beta)}\right] \operatorname{Cov}\left(\widehat{E}_{t} \pi_{t+1}, y_{t}\right) \\
& +\frac{\beta \lambda(1-\lambda)}{(1-\beta \lambda)^{3}} \sigma_{\varepsilon}^{2}+\frac{\beta^{2}(1-\lambda)^{3}}{(1-\beta \lambda)^{3}} \operatorname{Var}\left(\widehat{E}_{t} \pi_{t+1}\right)
\end{aligned}
$$


which can be divided by equation (A.4) to obtain an expression for $\operatorname{Corr}\left(e r r_{t+1}^{\mathrm{pc} \mid \mathrm{a}}, e r r_{t}^{\mathrm{pc} \mid \mathrm{a}}\right)$.

\section{A.2 Inflation Generated Using Phillips Curve Forecast}

Now consider the case when the representative agent employs the (rational) Phillips curve forecast (11). In equilibrium, inflation is governed by the rational law of motion (4). Both the adaptive forecast and the Phillips curve forecast are unbiased, such that $E\left(\operatorname{err}_{t+1}^{\mathrm{a} \mid \mathrm{pc}}\right)=$ $E\left(e r r_{t+1}^{\mathrm{pc|} \mid \mathrm{pc}}\right)=0$. Starting from (28), the fitness measure for the adaptive forecast is given by

$$
\begin{aligned}
M S E^{\mathrm{a} \mid \mathrm{pc}}= & \frac{\gamma^{2}\left[(1-\lambda)^{2}+2 \rho(1-\rho)(1-\lambda)\right]}{(1-\rho \beta)^{2}\left(1-\rho^{2}\right)} \sigma_{u}^{2}+\left(1+\lambda^{2}\right) \sigma_{\varepsilon}^{2} \\
& +(1-\lambda)^{2} \operatorname{Var}\left(\widehat{E}_{t} \pi_{t+1}^{\mathrm{re}}\right)-\frac{2 \gamma \rho(\rho-\lambda)(1-\lambda)}{(1-\rho \beta)} \operatorname{Cov}\left(\widehat{E}_{t} \pi_{t+1}^{\mathrm{re}}, y_{t}\right),
\end{aligned}
$$

where $\operatorname{Var}\left(\widehat{E}_{t} \pi_{t+1}^{\mathrm{re}}\right)$ and $\operatorname{Cov}\left(\widehat{E}_{t} \pi_{t+1}^{\mathrm{re}}, y_{t}\right)$ can be computed from the recursion $\widehat{E}_{t} \pi_{t+1}^{\mathrm{re}}=$ $\lambda \pi_{t}^{\mathrm{re}}+(1-\lambda) \widehat{E}_{t-1} \pi_{t}^{\mathrm{re}}$ The results are

$$
\begin{aligned}
\operatorname{Var}\left(\widehat{E}_{t} \pi_{t+1}^{\mathrm{re}}\right) & =\frac{\gamma^{2} \lambda}{(1-\rho \beta)^{2}\left(1-\rho^{2}\right)(2-\lambda)}\left[\frac{1+\rho(1-\lambda)}{1-\rho(1-\lambda)}\right] \sigma_{u}^{2}+\left(\frac{\lambda}{2-\lambda}\right) \sigma_{\varepsilon}^{2}, \\
\operatorname{Cov}\left(\widehat{E}_{t} \pi_{t+1}^{\mathrm{re}}, y_{t}\right) & =\frac{\gamma \lambda}{(1-\rho \beta)\left(1-\rho^{2}\right)[1-\rho(1-\lambda)]} \sigma_{u}^{2},
\end{aligned}
$$

where, since $\operatorname{Cov}\left(\widehat{E}_{t} \pi_{t+1}^{\mathrm{re}}, y_{t}\right)>0$, the adaptive forecast tracks movements in the driving variable.

It can be shown that the covariance of sequential forecast errors is given by

$$
\begin{aligned}
\operatorname{Cov}\left(\operatorname{err}_{t+1}^{\mathrm{a} \mid \mathrm{pc}}, \operatorname{err}_{t}^{\mathrm{a} \mid \mathrm{pc}}\right)= & \frac{\gamma^{2}}{(1-\rho \beta)^{2}\left(1-\rho^{2}\right)}\left\{\frac{\rho(\rho-\lambda)[1-\lambda+\rho(1-\rho)]}{1-\rho^{2}}-\lambda(1-\lambda)\right\} \sigma_{u}^{2} \\
& -\lambda[1-\lambda(1-\lambda)] \sigma_{\varepsilon}^{2}+(1-\lambda)^{3} \operatorname{Var}\left(\widehat{E}_{t} \pi_{t+1}^{\mathrm{re}}\right) \\
& -\frac{\gamma(1-\lambda)\left[\rho \lambda(1-\lambda)-(\rho-\lambda)\left(1+\rho^{2}\right)\right]}{(1-\rho \beta)} \operatorname{Cov}\left(\widehat{E}_{t} \pi_{t+1}^{\mathrm{re}}, y_{t}\right) .
\end{aligned}
$$

where $\operatorname{Var}\left(\widehat{E}_{t} \pi_{t+1}^{\mathrm{re}}\right)$ and $\operatorname{Cov}\left(\widehat{E}_{t} \pi_{t+1}^{\mathrm{re}}, y_{t}\right)$ continue to be given by (A.7) and (A.8). Dividing the above equation by $M S E^{\mathrm{a} \mid \mathrm{pc}}=\operatorname{Var}\left(e r r_{t+1}^{\mathrm{a} \mid \mathrm{pc}}\right)$ from (A.6) yields a complicated expression for $\operatorname{Corr}\left(e r r_{t+1}^{\mathrm{a} \mid \mathrm{pc}}, e r r_{t}^{\mathrm{a} \mid \mathrm{pc}}\right)$.

For the last of the four cases, we start from (29). The fitness measure for the rational Phillips curve forecast is given by

$$
M S E^{\mathrm{pc} \mid \mathrm{pc}}=\frac{\gamma^{2}}{(1-\rho \beta)^{2}} \sigma_{u}^{2}+\sigma_{\varepsilon}^{2} .
$$

The covariance of sequential forecast errors is given by

$$
\operatorname{Cov}\left(e r r_{t+1}^{\mathrm{pc} \mid \mathrm{pc}}, e r r_{t}^{\mathrm{pc} \mid \mathrm{pc}}\right)=0
$$

which is the standard result that forecast errors are serially uncorrelated under rational expectations. 


\section{B Appendix: Amplitude of Variation in 20-Year Rolling Sum- mary Statistics}

Table B.1: 20-Year Rolling Summary Statistics, Raw and Detrended Data

\begin{tabular}{|c|c|c|c|c|c|}
\hline \multirow[b]{4}{*}{ Statistic } & \multicolumn{2}{|c|}{ U.S. Data } & \multicolumn{3}{|c|}{ Model Simulations } \\
\hline & CPI & GDP-PI & & $\mathrm{CE}$ & $\mathrm{CE}$ \\
\hline & 1871.Q1 to & 1949.Q1 to & & Constant & Variable \\
\hline & 2004.Q4 & 2004.Q4 & $\mathrm{RE}$ & Gain & Gain \\
\hline \multirow{2}{*}{$\frac{\text { Mean }\left(\pi_{t}\right)}{\operatorname{Max} .}$} & 0.062 & 0.056 & $0 \cap 0 \Omega$ & 0 030 & $0 \cap 060$ \\
\hline & $\begin{array}{l}0.002 \\
0.006\end{array}$ & $\begin{array}{l}0.030 \\
0.002\end{array}$ & $\begin{array}{l}0.000 \\
0.001\end{array}$ & $\begin{array}{l}0.039 \\
0.002\end{array}$ & 0.007 \\
\hline \multirow{2}{*}{ Min. } & -0.031 & 0.021 & -0.005 & -0.068 & -0.095 \\
\hline & -0.009 & -0.002 & -0.001 & -0.002 & -0.006 \\
\hline \multirow{2}{*}{$\frac{\text { Std. Dev. }\left(\pi_{t}\right)}{\operatorname{Max} .}$} & 0.129 & 0029 & 0013 & 0037 & 0121 \\
\hline & $\begin{array}{l}0.129 \\
0.125\end{array}$ & $\begin{array}{l}0.029 \\
0.020\end{array}$ & $\begin{array}{l}0.013 \\
0.013\end{array}$ & $\begin{array}{l}0.037 \\
0.017\end{array}$ & $\begin{array}{l}0.121 \\
0.088\end{array}$ \\
\hline \multirow{2}{*}{ Min. } & 0.015 & 0.010 & 0.008 & 0.013 & 0.007 \\
\hline & 0.013 & 0.007 & 0.007 & 0.009 & 0.007 \\
\hline \multirow{2}{*}{$\frac{\text { Skew. }\left(\pi_{t}\right)}{\operatorname{Max} .}$} & 313 & & & 005 & 187 \\
\hline & $\begin{array}{l}3.13 \\
2.56\end{array}$ & $\begin{array}{l}2.41 \\
4.21\end{array}$ & $\begin{array}{l}0.89 \\
0.80\end{array}$ & $\begin{array}{l}0.95 \\
0.90\end{array}$ & $\begin{array}{l}1.81 \\
3.42\end{array}$ \\
\hline \multirow{2}{*}{ Min. } & -0.75 & 0.26 & -0.62 & -1.31 & -1.61 \\
\hline & -1.02 & -0.58 & -0.75 & -0.52 & -1.10 \\
\hline \multirow{2}{*}{$\frac{\text { Kurt. }\left(\pi_{t}\right)}{\operatorname{Max} .}$} & & & & 563 & \\
\hline & $\begin{array}{l}17.1 \\
16.1\end{array}$ & $\begin{array}{l}13.5 \\
30.5\end{array}$ & $\begin{array}{l}4.00 \\
4.99\end{array}$ & $\begin{array}{l}5.03 \\
4.49\end{array}$ & $\begin{array}{c}8.23 \\
22.11\end{array}$ \\
\hline \multirow{2}{*}{ Min. } & 2.13 & 2.12 & 2.08 & 1.67 & 1.48 \\
\hline & 2.56 & 2.24 & 2.11 & 2.15 & 2.22 \\
\hline \multirow{2}{*}{$\frac{\operatorname{Corr}\left(\pi_{t}, \pi_{t-1}\right)}{\operatorname{Max} .}$} & 0.89 & 0.91 & 0.47 & 0.88 & 0.95 \\
\hline & 0.71 & 0.65 & 0.34 & 0.49 & 0.73 \\
\hline \multirow{2}{*}{ Min. } & 0.13 & 0.50 & -0.15 & 0.13 & -0.23 \\
\hline & 0.07 & 0.15 & -0.25 & -0.20 & -0.25 \\
\hline
\end{tabular}

Notes: For each statistic, the top number refers to raw data while the bottom number refers to detrended data. The detrended data are obtained using the band pass filter of Christiano and Fitzgerald (2003). Model statistics are computed from a 2000-quarter simulation after dropping 200 quarters. The variable gain $\mathrm{CE}$ model uses a 20-year (80-quarter) rolling sample period for computing the perceived signal-to-noise ratio $\phi$. Parameter values: $\beta=0.98, \gamma=0.03, \rho=0.90, \sigma_{\varepsilon}=\sigma_{u}=0.01$. 


\section{References}

Adam, K. and M. Padula (2003). "Inflation dynamics and subjective expectations in the United States," European Central Bank, Working Paper No. 222.

Amato, J. and T. Laubauch. (2003). "Rule-of-thumb behavior and monetary policy," European Economic Review, 47,791-831

Ang, A., G. Bekaert, and M. Wei. (2005). "Do Macro variables, asset markets, or surveys forecast inflation better?" National Bureau of Economic Research, Working Paper 11538.

Arthur, W.B. (1989). "Competing technologies, increasing returns, and lock-in by historical small events," Economic Journal, 99, 116-131.

Ascari, G. (2004). "Staggered prices and trend inflation: some nuisances," Review of Economic Dynamics, 7, 642-667.

Atkeson, A. and L.E. Ohanian. (2001). "Are Phillips curves useful for forecasting inflation?" FRB Minneapolis Quarterly Review, Winter, 2-11.

Ball, L. (2000). "Near-rationality and inflation in two monetary regimes," National Bureau of Economic Research, Working Paper 7988.

Ball, L., N.G. Mankiw, and R. Reis. (2005). "Monetary Policy for inattentive economies," Journal of Monetary Economics, 52, 703-725.

Barsky, R.B. (1987). "The Fisher hypothesis and the forecastability and persistence of inflation," Journal of Monetary Economics, 19, 3-24.

Blinder, A.S. (1982). "The anatomy of double-digit inflation in the 1970s", in R. Hall, ed., Inflation: Causes and Effects. Chicago: University of Chicago Press, pp. 261-282.

Branch, W.A. (2004). "Theory of rationally heterogeneous expectations: evidence from survey data on inflation expectations," Economic Journal, 114, 592-621.

Buiter, W.H., and I. Jewitt. (1981). "Staggered wage setting with real wage relativities: Variations on a theme of Taylor," The Manchester School, 49, 211-228.

Calvo, G.A. (1983). "Staggered prices in a utility maximizing framework," Journal of Monetary Economics, 12, 383-398.

Carroll, C. (2003). "Macroeconomic expectations of households and professional forecasters," Quarterly Journal of Economics, 118, 269-298.

Christiano, L.J. and T.J. Fitzgerald. (2003). "The band pass filter," International Economic Review, 44, 435-465.

Christiano, L.J., M. Eichenbaum, and C.L. Evans. (2005). "Nominal rigidities and the dynamic effects of a shock to monetary policy," Journal of Political Economy, 13, 1-45.

Cogley, T. and T.J. Sargent. (2002). "Evolving post-World War II U.S. inflation dynamics," in B. Bernanke and K. Rogoff, eds., NBER Macroeconomics Annual 2001. Cambridge MA: MIT Press, pp. 331-373.

Cogley, T. and T.J. Sargent. (2005). "Drifts and volatilities: monetary policies and outcomes in the post WWII U.S.," Review of Economic Dynamics, 8, 262-302.

Cogley, T. and A.M. Sbordone. (2005). "A search for a structural Phillips curve," Federal Reserve Bank of New York, Staff Report No. 203.

Collard, F. and H. Dellas. (2004). "The New Keynesian model with imperfect information and learning," Journal of Money Credit and Banking, forthcoming.

David, P. (1985). "Clio and the economics of QWERTY." American Economic Review, Papers and Proceedings, 75, 332-337.

Erceg, C.J. and A.T. Levin. (2003). "Imperfect credibility and inflation persistence," Journal of Monetary Economics, 50,915-944. 
Evans, G.W. and S. Honkapohja. (2001). Learning and expectations in economics. Princeton: Princeton University Press.

Evans, G.W. and G. Ramey. (2006). "Adaptive expectations, underparameterization, and the Lucas critique," Journal of Monetary Economics, 53, 249-264.

Fuhrer J.C. (1997). "The (un)importance of forward-looking behavior in price specifications," Journal of Money Credit and Banking, 29, 338-350.

Fuhrer J.C. (2005). "Intrinsic and inherited inflation persistence," Federal Reserve Bank of Boston, Working Paper No. 05-8.

Fuhrer J.C. and G. Moore. (1995). "Inflation persistence," Quarterly Journal of Economics, 110, 127-160.

Friedman, M. (1968). "The role of monetary policy," American Economic Review, 58, 1-17.

Friedman, B.M. (1979). "Optimal expectations and the extreme information assumptions of rational expectations models," Journal of Monetary Economics, 5, 23-41.

Gaspar, V., F. Smets, and D. Vestin. (2006). "Optimal monetary policy under adaptive learning," European Central Bank, Working Paper.

Galí, J. and M. Gertler. (1999). "Inflation dynamics: A structural econometric analysis," Journal of Monetary Economics, 44, 195-222.

Galí, J., M. Gertler, and J. D. López-Salido. (2005). "Robustness of the estimates of the hybrid New Keynesian Phillips curve," Journal of Monetary Economics, 52, 1107-1118.

Gardner, E.S., Jr. (1985). "Exponential smoothing: The state of the art," Journal of Forecasting, 4, 1-28.

Goodfriend, M. (1993). "Interest rate policy and the inflation scare problem: 1979-1992," Federal Reserve Bank of Richmond, Economic Quarterly, 79(1), 1-24.

Harvey, A.C. (1993). Time Series Models. MIT Press.

Huh, C.G. and K.J. Lansing (2000). "Expectations, credibility, and disinflation in a small macroeconomic model," Journal of Economics and Business, 51, 51-86.

Hommes, C. and G. Sorger. (1998). "Consistent expectations equilibria," Macroeconomic Dynamics, 2, 287-321.

Ireland. P.N. (2006). "Changes in the Federal Reserve's inflation target: Causes and consequences," Boston College, Working Paper.

King, R.G. and M.W. Watson. (1994). "The post-war U.S. Phillips curve: A revisionist econometric history," Carnegie-Rochester Conference Series on Public Policy, 41, 157-219.

Klein, B. (1978), "The measurement on long- and short-term price uncertainty: A moving regression time series analysis," Economic Inquiry, 16, 438-452.

Kozicki, S. and P.A. Tinsley. (2002), "Alternative sources of the lag dynamics of inflation," Price Adjustment and Monetary Policy Conference Proceedings, Bank of Canada.

Kozicki, S. and P.A. Tinsley. (2005), "Permanent and transitory policy shocks in an empirical macro model with asymmetric information," Journal of Economic Dynamics and Control, 29, $1985-2015$.

Lansing, K.J. (2006). "Lock-in of extrapolative expectations in an asset pricing model," Macroeconomic Dynamics, 10, 317-348.

Lansing, K.J. and B. Trehan (2003). "Forward-looking behavior and optimal discretionary monetary policy," Economics Letters, 81, 249-256.

Laxton, D., D. Rose, and D. Tambakis. (1999). "The U.S. Phillips curve: The case for asymmetry," Journal of Economic Dynamics and Control, 23, 1459-1485.

Levin, A.T. and J.M. Piger. (2004). "Is inflation persistence intrinsic in industrial economies?" European Central Bank, Working Paper No. 334. 
Levin, A.T. and R. Moessner. (2005). "Inflation persistence and monetary policy design: An overview" European Central Bank, Working Paper No. 539.

Lucas, R.E., Jr. (1972). "Expectations and the neutrality of money," Journal of Economic Theory, 4, 103-124.

Lucas, R.E., Jr. (1973). "Some international evidence on output-inflation trade-offs," American Economic Review, 63, 326-334.

Mankiw, N.G. (2001). "The inexorable and mysterious tradeoff between inflation and unemployment," Economic Journal, 111, C45-C61.

Mankiw, N.G. and R. Reis. (2002). "Sticky information versus sticky prices: A proposal to replace the New Keynesian Phillips curve," Quarterly Journal of Economics, 117, 1295-1328. Mankiw, N.G., R. Reis, and J. Wolfers. (2004). "Disagreement about inflation expectations," in M. Gertler and K. Rogoff, eds., NBER Macroeconomics Annual 2003. Cambridge MA: MIT Press, pp. 209-248.

Marques, C.R. (2004). "Inflation persistence: Facts or artefacts?" European Central Bank, Working Paper No. 371.

Mash R. (2004). "Optimizing microfoundations for inflation persistence," Oxford University Department of Economics, Working Paper 183.

McCulloch, J.H. (2005). "The Kalman foundations of adaptive least squares, with application to U.S. inflation," Ohio State University, Working Paper.

Milani, F. (2005). "Adaptive learning and inflation persistence," Princeton University, Working Paper.

Muth, J.F. (1960). "Optimal properties of exponentially weighted forecasts," Journal of the American Statistical Association, 55, 299-306.

Neiss, K.S. and E. Nelson. (2005). "Inflation dynamics, marginal cost, and the output gap: Evidence from three countries," Journal of Money Credit and Banking, 37, 1019-1045.

Orphanides, A. and J.C. Williams. (2005). "Imperfect knowledge, inflation expectations, and monetary policy," in B. Bernanke and M. Woodford, eds., The Inflation Targeting Debate. Chicago: University of Chicago Press, pp. 201-234.

Orphanides, A. and S. Van Norden. (2005). "The reliability of inflation forecasts based on output gap estimates in real time," Journal of Money Credit and Banking, 37, 583-601.

Phelps, E.S. (1967). "Phillips curves, expectations of inflation and optimal unemployment over time," Economica, 34, 254-281.

Piger, J.M. and R.H. Rasche. (2006). "Inflation: Do expectations trump the gap?" Federal Reserve Bank of St. Louis, Working Paper 2006-013A.

Pivetta, F. and R. Reis. (2004). "The persistence of inflation in the United States," Harvard University, Working Paper.

Roberts, J. (1997). "Is inflation sticky?" Journal of Monetary Economics, 39, 173-196.

Roberts, J. (2005). "How well does the New Keynesian sticky-price model fit the data?" Contributions to Macroeconomics, 5(1).

Rudd, J.B. and K. Whelan. (2005a). "New tests of the New-Keynesian Phillips curve," Journal of Monetary Economics, 53, 1167-1181.

Rudd, J.B. and K. Whelan. (2005b). "Modeling inflation dynamics: A critical review of recent research," Federal Reserve Board, Finance and Economics Discussion Series Paper 2005-66.

Rudd, J.B. and K. Whelan. (2005c). "Does labor's share drive inflation?" Journal of Money, Credit, and Banking, 37, 297-312.

Rudebusch, G.D. (2002). "Assessing nominal income rules for monetary policy with model and data uncertainty." Economic Journal, 112, 402-432. 
Sahuc, J.-G. (2006). "Partial indexation, trend inflation, and the hybrid Phillips curve," Economics Letters, 90, 42-50.

Sargent, T. (1971). "A note on the 'accelerationist' controversy," Journal of Money, Credit, and Banking, 3, 721-725.

Sargent, T.J. (1999). The Conquest of American Inflation. Princeton: Princeton University Press.

Sheedy, K.D. (2005). "Structural inflation persistence," University of Cambridge, Working Paper.

Sims, C.A. and T. Zha. (2006). "Were there regime switches in U.S. monetary policy?" American Economic Review, 96, 54-81.

Steinsson, J. (2003). "Optimal monetary policy in an economy with inflation persistence," Journal of Monetary Economics, 50, 1425-1456.

Stock, J.H. and M.W. Watson. (1996). "Evidence on structural instability in macroeconomic time series relations," Journal of Business and Economic Statistics, 14, 11-30.

Stock, J.H. and M.W. Watson. (2005). "Has inflation become harder to forecast?" Working Paper.

Volcker, P.A. (1979). "Statement" before the Joint Economic Committee, Federal Reserve Bulletin, 65 (November), 888-890.

Warren, G.F. and F.A. Pearson. (1935). Gold and Prices. New York: John Wiley \& Sons.

Whelan, K. (2006). "Staggered price contracts and inflation persistence: Some general results," International Economic Review, forthcoming.

Woodford, M. (2003). Interest and prices: Foundations of a theory of monetary policy. Princeton: Princeton University Press.

Woodford, M. (2005). "Robustly optimal monetary policy with near-rational expectations," Columbia University, Working Paper. 